\title{
Lamina-associated domains: peripheral matters and internal affairs
}

\author{
Nolwenn Briand ${ }^{1,2}$ and Philippe Collas ${ }^{1,2^{*}}$
}

\author{
*Correspondence: philippe.collas@ \\ medisin.uio.no \\ ${ }^{1}$ Department of Molecular Medicine, \\ Faculty of Medicine, University of \\ Oslo, PO Box 1112 Blindern, 0317 \\ Oslo, Norway \\ ${ }^{2}$ Department of Immunology and \\ Transfusion Medicine, Oslo \\ University Hospital, 0424 Oslo, \\ Norway
}

\begin{abstract}
At the nuclear periphery, associations of chromatin with the nuclear lamina through lamina-associated domains (LADs) aid functional organization of the genome. We review the organization of $L A D s$ and provide evidence of $L A D$ heterogeneity from cell ensemble and single-cell data. LADs are typically repressive environments in the genome; nonetheless, we discuss findings of lamin interactions with regulatory elements of active genes, and the role lamins may play in genome regulation. We address the relationship between LADs and other genome organizers, and the involvement of LADs in laminopathies. The current data lay the basis for future studies on the significance of lamin-chromatin interactions in health and disease.
\end{abstract}

Keywords: 3D genome, Chromatin, LAD, Lamin A mutation, Nuclear envelope, Nuclear lamin, Radial positioning

\section{Introduction}

A snapshot of the genome in three dimensions

In the eukaryotic nucleus, individual chromosomes occupy non-random territories and a radial (i.e., center-to-periphery) disposition enabled by sequestering specific chromosomal domains to the nuclear envelope. Current views of the three-dimensional (3D) genome depict a hierarchical architecture of chromatin [1,2]. Chromosome conformation capture combined with high-throughput sequencing (a method called $\mathrm{Hi}-\mathrm{C}$ [3]) makes it possible to map interactions within and between chromosomes across genomes [4]. Hi-C data reveal, on a multi-megabase $(\mathrm{mb})$ scale, a segregation of the genome into open and active "A" compartments, and more closed and inactive "B" compartments. Within compartments, topologically associated domains (TADs) represent regions with a high frequency of chromosomal interactions [5]. Whereas TAD boundaries are overall well conserved, contacts within TADs can vary, partly specifying regulatory contacts. Linearly non-contiguous TADs can also contact each other, defining long-range interactions that can vary between cell types and during differentiation [6-8]. Spatial genome conformation is also modulated by interactions of chromosomes with landmarks such as nucleoli [9], splicing speckles [10], and the nuclear envelope [11], all providing tethering points for chromatin.

(c) The Author(s). 2020 Open Access This article is licensed under a Creative Commons Attribution 4.0 International License, which permits use, sharing, adaptation, distribution and reproduction in any medium or format, as long as you give appropriate credit to the original author(s) and the source, provide a link to the Creative Commons licence, and indicate if changes were made. The images or other third party material in this article are included in the article's Creative Commons licence, unless indicated otherwise in a credit line to the material. If material is not included in the article's Creative Commons licence and your intended use is not permitted by statutory regulation or exceeds the permitted use, you will need to obtain permission directly from the copyright holder. To view a copy of this licence, visit http//creativecommons.org/licenses/by/4.0/. The Creative Commons Public Domain Dedication waiver (http://creativecommons.org/publicdomain/zero/1.0/) applies to the data made available in this article, unless otherwise stated in a credit line to the data. 
The nuclear envelope as a genome organizer

At the nuclear periphery, multiple associations of chromatin with the nuclear envelope generate a radial topology of the genome enabling a spatio-temporal regulation of replication and transcription [11]. The nuclear envelope consists of an outer nuclear membrane (ONM) continuous with the endoplasmic reticulum, an inner nuclear membrane (INM) facing the nucleoplasm, nuclear pore complexes (NPCs) and subjacent to the INM, the nuclear lamina, and a meshwork of filament proteins called A- and B-type lamins [12] (Fig. 1a). Radial genome conformation involves interactions of active genome regions with NPCs and of overall silent parts of the genome with the INM and with the nuclear lamina through lamina-associated domains (LADs) [18].

LADs emerge as genomic elements that are both shaped by, and shape, epigenomic states and high-order genome architecture. Mutations in nuclear lamins causing disease can disrupt this organization [19]. Lamin mutations often lead to nuclear envelope deformations and disorganization of peripheral heterochromatin [20], phenotypes also seen in cancer [21, 22] and during normal and pathological aging [23-27]. Here, we highlight current knowledge on the composition and stochastic nature of LADs. We

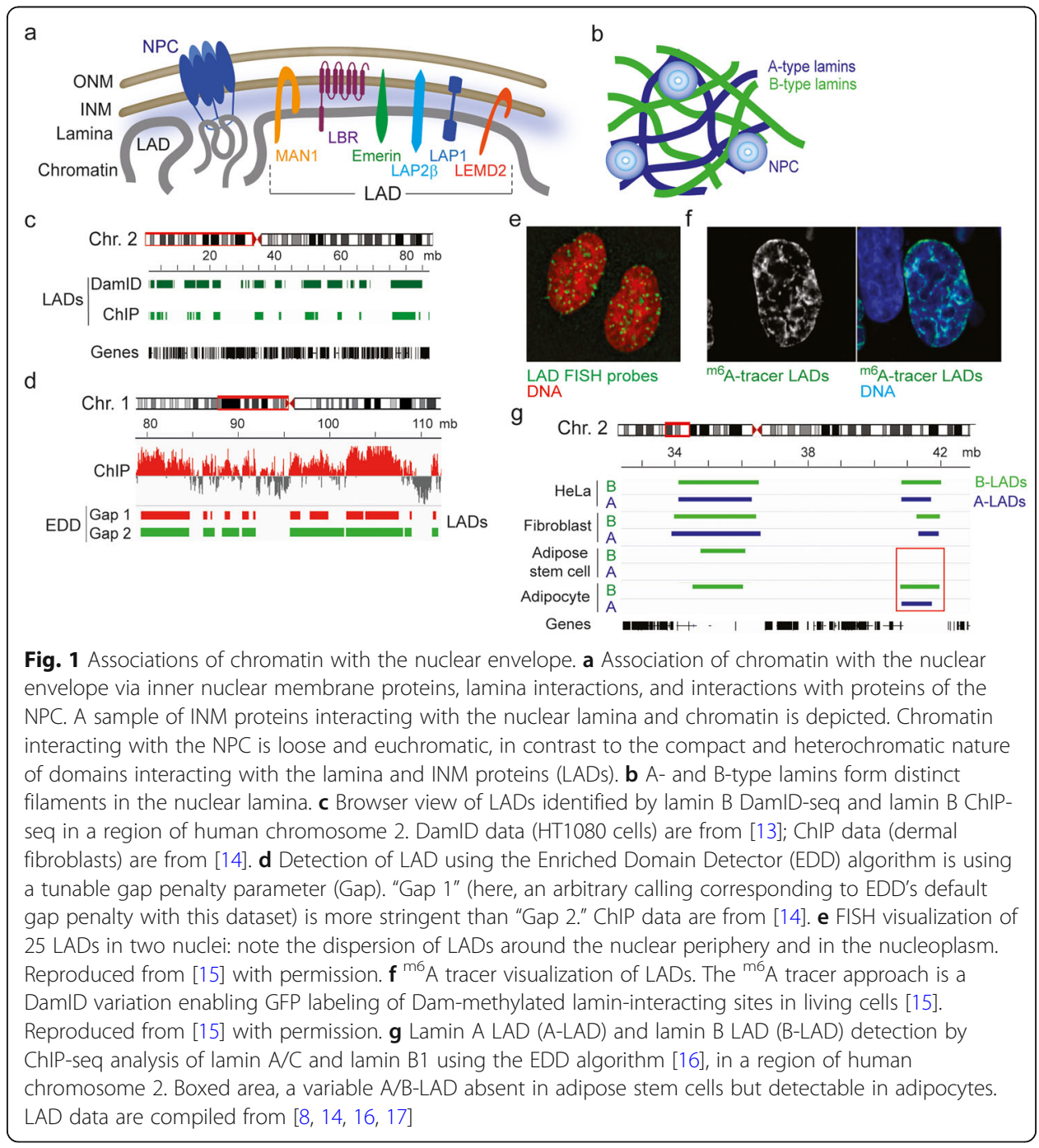


discuss evidence of domain-type and punctual lamin-chromatin interactions at the nuclear periphery and in the nuclear interior, and on how these influence 3D genome architecture and gene expression. We assess how disease-causing mutations in nuclear lamins affect LADs, and provide perspectives on future work expected to shed new light on the roles of lamin-chromatin interactions in health and disease.

\section{Architecture of the nuclear lamina}

The nuclear lamina is a heterogeneous meshwork of intermediate filaments

The nuclear lamina consists of a meshwork of type $\mathrm{V}$ intermediate filaments, the nuclear lamins, and associated proteins [28]. It interfaces and interacts with the INM and chromatin, tethering heterochromatin to the nuclear periphery (Fig. 1a). The main mammalian lamins are lamins $\mathrm{A}$ and $\mathrm{C}$ (also called lamin $\mathrm{A} / \mathrm{C}$ ), splice variants of the $L M N A$ gene, and lamins $\mathrm{B} 1$ and $\mathrm{B} 2$, products of the LMNB1 and LMNB2 genes. Lamins consist of an $\mathrm{N}$-terminal head domain, a coiled-coil central rod domain, and a globular C-terminal tail domain containing an immunoglobulin (Ig)-like fold which in vitro binds nucleosomes [29]. Assembly of the nuclear lamina occurs via polymerization involving homodimerization, head-to-tail assembly of homodimers, and antiparallel assembly of the head-to-tail polymers into filaments [28]. A- and B-type lamins undergo step-wise maturation leading to permanent $\mathrm{C}$-terminal farnesylation and tethering of B-type lamins in the INM, whereas lamin A is further processed Cterminally, untethering it from the INM. Lamin $C$ is never farnesylated, and both lamins $\mathrm{A}$ and $\mathrm{C}$ are found at the nuclear lamina and in the nucleoplasm where they interact with chromatin [30-32] and regulate chromatin mobility [33]. Lamins A and C also differentially associate with NPC subunits [34] while A- and B-type lamins, by interacting with distinct INM and chromatin components, seem to play distinct roles in nuclear lamina organization $[35,36]$. In addition, post-translational modifications of lamins, including phosphorylation [37], O-GlcNAcylation (which is specific to lamin A, not $\mathrm{C}$ or $\mathrm{B}$ ) [38], and acetylation [39], contribute to the stability and function of the lamin networks. These observations reflect the complexity of the nuclear lamina and of its role in organizing higher-order chromatin topology.

\section{The nuclear lamina is a heterogeneous polymer structure}

Examination of the nuclear lamina at different scales and resolutions shows that Aand B-type lamins assemble into distinct polymers and form distinct networks (Fig. 1b). Fluorescence resonance energy transfer signals between lamins A and B co-expressed in mammalian cells reveal heterotypic and homotypic interactions between these lamin subtypes in the lamina [40]. Homotypic interactions prevail while heterotypic interactions occur only between A- or B-type lamin homodimers [40]. This suggests that Aand B-type lamins assemble into distinct homopolymers that are able to interact within the lamina. High- and super-resolution microscopy imaging further reveals distinct Aand B-type lamin networks [36, 41] forming distinct "microdomains" [35]. Direct stochastic optical reconstruction microscopy confirms the existence of non-overlapping networks of lamins $\mathrm{A}$ and $\mathrm{B}$, and of distinct lamins $\mathrm{A}$ and $\mathrm{C}$ networks, indicating that lamin subtypes preferentially self-associate (as A-A, C-C, B-B) [34]. 
Cryo-electron tomography insights into the molecular arrangement of the nuclear lamina reveal a fiber-like morphology of lamin networks decorated with globules, forming filaments [28]. These filaments are packaged into a 14-nm-thick layer (the lamina) but make up only $\sim 12 \%$ of the lamina volume. Large and variable voids free of lamins are occupied by other proteins and chromatin, emphasizing the structural heterogeneity of the nuclear lamina. Differential labeling of A- and B-type lamins further indicates that their densities and spatial distributions differ, supporting their segregation in the lamina [28]. Additionally, the broad persistence length distribution of lamin filamentsthat is, the length under which the lamin polymer behaves as a flexible chain and above which it behaves as a rigid rod-reflects a large degree of flexibility [28] and creates possibilities for A- and B-type lamins to interact with specific protein partners and chromosomal domains.

\section{Tethering the genome at the nuclear periphery through lamina-associated domains}

Multiple mediators of chromatin interactions with the nuclear envelope

The nuclear periphery is a site of cooperative interactions between the nuclear envelope and chromatin (Fig. 1a). Proteins of the NPC can interact with chromatin, mainly with active regions [11]. INM transmembrane proteins form tissue-specific complexes with lamins and, within these complexes, cooperate to functionally organize chromatin [4246]. Lamin B receptor (LBR) binds lamin B and the H3K9me3-binding chromobox protein homolog 5 (CBX5) [47], providing a tether for heterochromatin at the nuclear envelope in developing tissues [48]. Thymopoietin/lamina-associated polypeptide (LAP) $2 \beta$ also binds B-type lamins and provides docking sites for chromatin via interactions with histones [49], the DNA-bridging protein barrier-to-autointegration factor [50], and LAP2 $\alpha$ [51]. Other INM proteins containing a LEM (LAP2-emerin-MAN1) domain, such as emerin, LEMD2, and LEMD3/MAN1, also bind lamins and chromatin [52].

LAP2 $\beta$ and emerin interact with histone deacetylase HDAC3 [53-55]. HDAC3 contributes to the repressive environment of the nuclear periphery through histone deacetylation [54] and, together with emerin, regulates myogenic gene radial position and expression [56]. Moreover during myogenesis, muscle-specific INM proteins seem to be involved in the radial repositioning of a subset of genes that are downregulated [45]. For example, the Nid1 gene is repressed in early stages of myogenesis in a manner that correlates with lamina association and a peripheral localization dependent on the INM protein NET39 [45]. Many other genes behave similarly or, in contrast, are downregulated without any lamina association or radial repositioning [45]. Histone methylation is another important feature of the nuclear periphery where histone methyltransferases play a role in sequestering heterochromatin to the nuclear envelope [57-59]. Euchromatin-associated factors and histone acetylation have also been suggested to contribute to the radial segregation of euchromatin and heterochromatin [60]. The multiplicity of chromatin interactions with INM proteins and the lamina, together with the overall heterochromatic nature of the nuclear periphery, contribute to generating concentric "zones" of gene expression with a repressive environment at the nuclear periphery $[1,61,62]$, zones of DNA replication timing with late-replicating DNA enriched 
at the periphery [63], and in some cell types, tissue specificity in sequestering loci to the nuclear envelope [42].

\section{Mapping LADs using sequencing approaches}

The nuclear lamina emerges as an organizer of the radial disposition of chromatin. Evidence of interactions of chromatin with the lamina was not provided until van Steensel and colleagues mapped such associations and coined the term "lamina-associated domain" (LAD) [18] (Fig. 1a). The first report of LADs relied on DamID (Dam identification), a proximity DNA labeling method where the bacterial DNA adenine methyltransferase (Dam) was fused to lamin B1 [18]. Dam is targeted to lamin-binding regions where it methylates adenines at GATC sites to generate 6-methyl-adenine $\left({ }^{\mathrm{m} 6} \mathrm{~A}\right)$, which does not normally occur in eukaryotes. Regions containing ${ }^{\mathrm{m} 6} \mathrm{~A}$ are selectively amplified, and products identified by hybridization to DNA microarrays or highthroughput sequencing (DamID-seq) [13, 18, 64] (Fig. 1c). LADs have also been identified by chromatin immunoprecipitation (ChIP)-seq of lamins A/C or B from chromatin fragmented by micrococcal nuclease digestion or by sonication $[16,27,32,65,66]$ (Fig. 1c). Despite methodological differences [67], LADs mapped by DamID or ChIP overlap overall [16] (Fig. 1c).

\section{The bioinformatics factor in LAD identification}

How are LADs bioinformatically identified? Accumulating lamin DamID or ChIP sequencing reads to a reference genome is not sufficient to determine areas of enrichment because the overall low level of lamin enrichment on the genome makes it challenging to differentiate occupancy from background. Some lamin ChIP-seq analyses rely on a read count- and threshold-based method in a sliding window [27]. Algorithms detecting domains rather than peaks have however been designed. An algorithm based on the detection of sharp transitions in binarized lamin-genome interactions using a sliding window was used in the pioneering mapping of LADs [18]. DamID data can also be quantile-normalized and segmented by a modified circular binary segmentation algorithm originally designed to detect DNA copy number differences, by testing for significant breakpoints throughout a binned genome [68]; this algorithm has been refined in the LADetector pipeline [69].

LAD detection from "background-adjusted-normalized" lamin ChIP-seq data using a two-state (lamin/no-lamin) hidden Markov model based on the RSEG peak caller has been applied to map changes in lamin B LADs during senescence [65]. RSEG segments the genome by identifying boundaries with high transition probabilities, but ignores the factual enrichment levels [16]. Other domain-calling algorithms such as BroadPeak or PeakRanger do not support the use of input chromatin reads (required to determine enrichment) or only incorporate input reads to validate identified peaks [16].

Given these insufficiencies, we have in 2014 released Enriched Domain Detector (EDD), a domain caller designed to identify LADs from ChIP-seq data [16]. Features of EDD are sensitivity to the width of lamin domains and robustness against background variations $[8,17,32]$. As with any other domain caller, the number of LADs detected with EDD can vary depending on fluctuations in lamin enrichment strength: a local dip in enrichment strength within a LAD can be detected as a break (calling two LADs) or 
ignored (one LAD) depending on a "gap penalty" setting (Fig. 1d). The definition of a LAD then may come down to a bioinformatics interpretation of a genomic domain enriched in lamins and does not imply a domain where lamin-chromatin interactions are uninterrupted $[16,17,70]$.

\section{Visualizing LADs in the nucleus}

While DamID and ChIP are instrumental in identifying LAD sequences, they do not provide information on the localization of LADs in the nucleus. This can be achieved by fluorescence in situ hybridization (FISH) using LAD sequences to design FISH probes (Fig. 1e). FISH can validate DamID- or ChIP-seq data, but the main strength of FISH is in the single-cell resolution of this approach $[15,68,69]$.

LADs can also be visualized in living cells. A DamID-derived imaging approach yielding a green fluorescent protein (GFP) ${ }^{\mathrm{m} 6} \mathrm{~A}$ labeling of DNA in contact with lamins (an ${ }^{~ " \mathrm{~m} 6} \mathrm{~A}$ tracer") allows visualization of DNA sequences that are or have been in contact with the lamina [15]. Lamin-interacting sequences retain the GFP signal even though the interaction no longer exists at the time of observation (Fig. 1f). GFP is fused to a catalytically inactive restriction endonuclease which binds methylated $G^{\mathrm{m}} \mathrm{ATC}$ sites, to visualize binding sites immediately after methylation. The method therefore enables a tracking of LADs in living cells and provides a "molecular contact memory" [15] of lamin interactions with chromatin.

\section{LADs constitute heterogeneous domains}

LADs are detected with various densities on all chromosomes, as domains ranging from $100 \mathrm{~kb}$ to $10 \mathrm{mb}$ with a median size of $0.5-1 \mathrm{mb}$ (Fig. 1g). LADs altogether make up to $40 \%$ of the genome, but as discussed later, this does not mean that $40 \%$ of the genome is bound to the lamina in all cells in a population. LADs overlap with regions of low gene density, typically $2-3$ genes per mb (human genome average is $\sim 8$ genes $/ \mathrm{mb}$ ); replicate in late S phase; and are enriched in B compartments [69, 71]. Accordingly, LADs are rich in di- and trimethylated histone H3 lysine 9 (H3K9me2 and H3K9me3), histone modifications of constitutive heterochromatin, and most genes in LADs are repressed or expressed at low levels $[16,18]$. While histone methylation is a mediator of this repressed state [57], histone deacetylation also determines repression in LADs, given the interactions of LAP2 $\beta$ with HDAC3 [54] and of A-type lamins with the sirtuins SIRT1 and SIRT6 [72], which together regulate expression of lamina-associated genes [56]. LADs therefore exhibit typical features of heterochromatin [18].

There are however nuances to this picture. On the one hand, LADs represent intrinsic repressive environments: insertion of reporter genes into LAD sequences is associated with lower expression than in inter-LAD regions [73]. Similarly, sequences determining LAD localization at the lamina inserted into non-LAD regions promote lamina tethering and transcriptional repression [55, 68, 74]. Changes in gene expression concordant with their association with the nuclear lamina have also been shown during differentiation $[17,45,64,75]$.

On the other hand, this relationship is not always straightforward. For example, expression of a subset of $\mathrm{T}$ cell-specific genes concurs with detachment of enhancers from the nuclear lamina after $\mathrm{T}$ cell activation, while these genes retain a peripheral 
localization [76]. In other instances, radial repositioning of a lac $O$ array in response to alterations in the level of specific INM proteins can occur without any obvious changes in gene expression [43]. This highlights an uncoupling between radial positioning and gene expression. Accordingly, there are also instances of persistent gene expression whether genes interact with or are released from lamins [77]. Further, periodic association and dissociation of genes from the lamina during the circadian cycle in mouse liver are uncoupled from changes in gene expression in LADs or in their vicinity [78]. Nuclear lamina association, therefore, is not the sole determinant of gene repression at the nuclear periphery.

In fact, at least $10 \%$ of genes found at the nuclear lamina are expressed $[8,16,18,75$, 79]. Using a promoter shuffling strategy where LAD promoters are placed into episomal or endogenous non-LAD contexts [80], three classes of promoters have been identified: "repressed LAD promoters" that become active when removed from their LAD context, "escaper promoters" active even when in a LAD, and "inactive promoters" inactive regardless of their LAD localization (Fig. 2a). So LADs appear to be structurally and functionally heterogeneous, with subdomains, possibly forming microloops not bound to lamins [81] escaping the repressive LAD context.

These observations raise the question of what defines a LAD. If a heterochromatic region is sequestered to the lamina (the very definition of a LAD), is being at the lamina necessary to maintain its heterochromatin identity? In the short term, the answer appears to be "no." However, long-term reduction of lamin B occurring in senescence models leads to a reshaping of heterochromatin and, over time, a shift in LAD organization [27]. This could reflect a more nuanced role for chromatin sequestration at the nuclear lamina, perhaps in helping maintain epigenetic states over time.

\section{LADs dynamically interact with A- and B-type lamins \\ Constitutive and variable LADs}

Some LADs occur consistently between cell types and even species, while others are more variable [13]. Constitutive LADs (cLADs) display typical features of heterochromatin, are enriched in repeat elements, and constitute structural elements of the genome tethering chromatin to the nuclear lamina. Variable LAD (vLADs) [13] are a common feature of differentiation and tend to harbor cell type-specific genes that are released from lamins upon lineage commitment [17, 45, 64, 82] (Fig. 1g, red box). This suggests that a fraction of vLADs is developmentally regulated. Most of the variation in vLADs occurs through shifts of LAD borders more frequently than entire LADs appearing and disappearing [64, 68, 77, 83] (Fig. 1g). This suggests that a core LAD structure plays a structural role in nuclear architecture while LAD borders may function in the regulation of expression of LAD-proximal genes $[68,70]$.

\section{Lamin A LADs and lamin B LADs}

Whereas most lamin A/C LADs ("lamin A LADs") and lamin B LADs overlap, there are also differences [16, 66, 77] (Fig. 1g) suggesting complementary roles of A- and Btype lamins in genome organization. ChIP-seq analysis of lamins $A / C$ and $B$ from micrococcal nuclease-digested HeLa cell chromatin reveals about one third of LAD genome coverage being unique to lamin $B$ and one fifth unique to lamin $A / C$ [66]. 


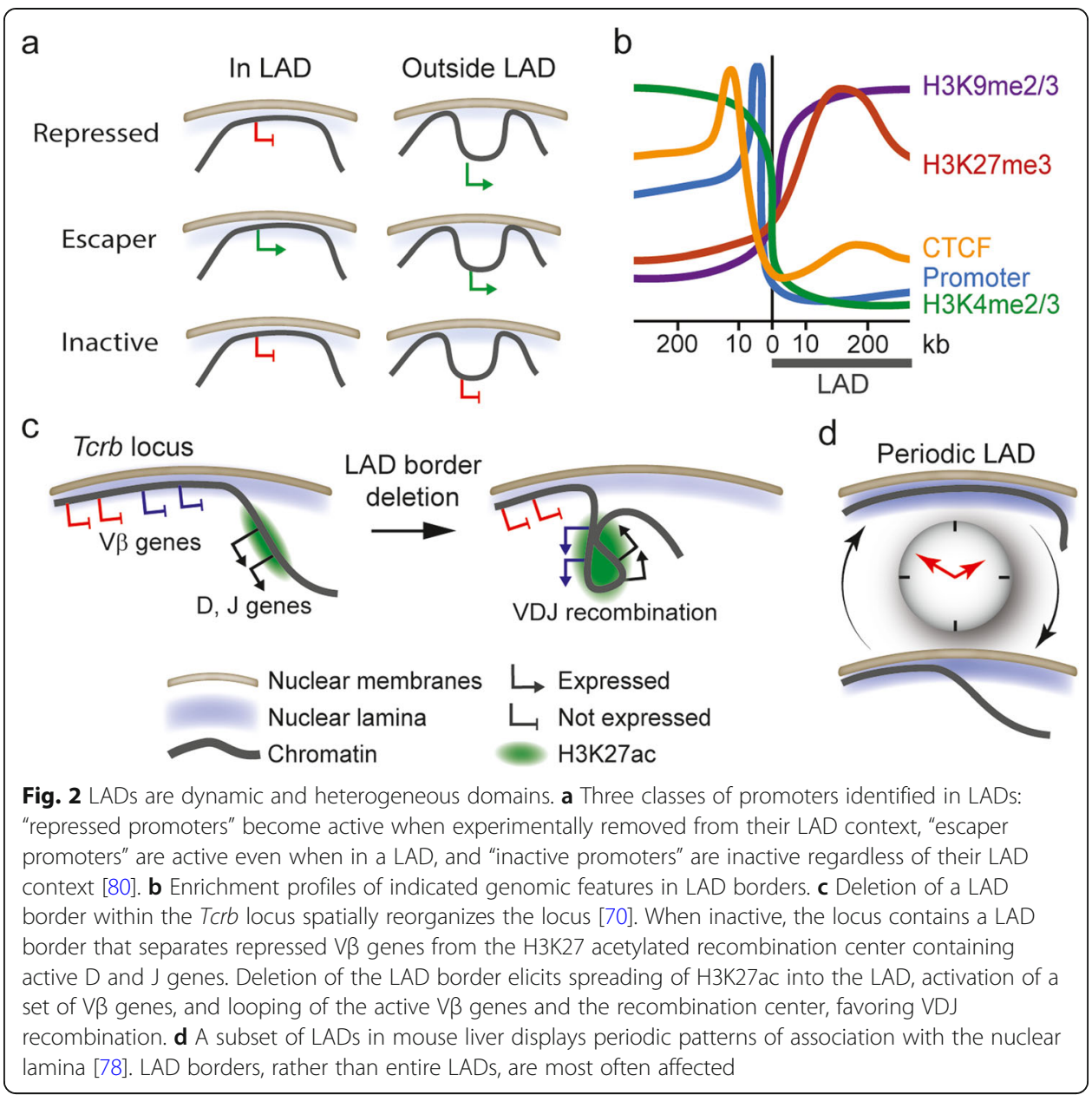

While LADs shared by both lamin types ("lamin A/B" LADs) are likely at the nuclear periphery, lamin A LADs reflect domains not reached by lamin $B$ at the periphery or in the nucleoplasm. Differential interactions of chromatin with A- or B-type lamins at the periphery may be explained by the distinct lamin A- and B-type filaments in the lamina [35] and the dynamic nature of these interactions [77]. Extending these findings, lamin $\mathrm{A}, \mathrm{A} / \mathrm{B}$, and $\mathrm{B}$ LADs can display differential loss or gain of lamin $\mathrm{A} / \mathrm{C}$ or $\mathrm{B}$ interactions, or switch lamin type $[8,17,77]$ (Fig. 1g).

What are the consequences of changes in lamin A versus lamin B LAD identity? According to the current data, surprisingly few. LAD reorganization does not correlate with changes in gene expression in LADs [77]. However, 3D genome modeling and FISH data concur in that being in a lamin A LAD or a lamin B LAD differently influences the radial positioning of loci, but this is likely locus-dependent [77]. Radial repositioning of a lamin A LAD also depends on whether a lamin B LAD is nearby [77]. Thus a lamin neighborhood may influence genome topology $[33,84]$ even though lamins are not directly associated with these regions. 


\section{At the (LAD) border}

LADs are typically delineated by abrupt borders. These are characterized by a sharp transition in gene density and gene expression, high promoter and CG dinucleotide density, enrichment in the insulator protein CCCTC-binding factor (CTCF), and abrupt changes in RNA Polymerase II and H3K4me2 [13, 18, 64, 68, 70] (Fig. 2b). Enrichment in H3K27me3 near LAD borders further suggests a role of Polycomb in LAD demarcation to segregate inactive from active genomic segments [68].

The importance of LAD borders has been exemplified at the $\mathrm{T}$ cell receptor Tcrb locus [70] (Fig. 2c). At the nuclear periphery, a LAD border separates repressed variable $\mathrm{V} \beta$ gene segments from the active recombination center containing $\mathrm{D}$ and $\mathrm{J}$ segments. Deletion of the LAD border leads to spreading of H3K27ac from the recombination center into the proximal LAD portion of the Tcrb locus, causing V $\beta$ gene segments to dissociate from the lamina and interact with the recombination center [70]. This is concordant with enhancer activation and increased VDJ recombination [70]. So LAD borders emerge as functionally important structural elements.

\section{LADs around the clock}

Circadian rhythms govern most of our metabolism and physiology [85]. More than 4000 genes exhibit oscillatory expression patterns with defined periodicities in virtually all organs. Circadian gene expression-that is, transcript levels oscillating with a 24-h period-is regulated by circadian patterns of transcription factor binding, histone modifications, and chromosomal interactions [86, 87]. Thus circadian rhythms are implicated in regulating some aspects of 3D genome architecture [88].

Evidence linking the nuclear envelope to circadian gene expression however remains scarce. A handful of circadian genes has been shown in human colon cancer cells to interact with the nuclear lamina in a circadian manner concordant with their repression [89]. In mouse liver, a subset of LAD borders display periodic interactions with lamin B during circadian time [78] (Fig. 2d). This suggests that some LADs may be regulated in a periodic fashion akin to the rhythmicity of chromosomal contacts [87]. Underlying mechanisms remain unknown but could involve periodic binding of lamina-targeting factors. The impact of periodic LADs on gene expression also strikingly remains totally unclear [78]. In fact, clock-control genes lie in an environment deprived of nuclear lamins, permissive to circadian transcription control [88].

\section{Targeting loci to the nuclear lamina}

The sharp transitions in genomic characteristics at LAD borders suggest functionality in genome organization. First, LAD borders seem to harbor sequences important for their radial position. Lamina-associated sequences have been reported as motifs able to target genomic sites to the nuclear periphery $[55,68]$. These are enriched in GAGA repeats which constitute binding sites for C-KROX/ZBTB7B, a zinc-finger and BTB/POZ domain-containing protein [55]. ZBTB7B interacts with HDAC3 and LAP2 $\beta$, suggesting implication of GAGA motifs not only in LAD targeting to the periphery but also in gene repression [55]. Lamina-associated sequences also reveal binding motifs for CTCF and the transcription factor Ying Yang 1 which, perhaps acting as a Polycomb group protein [90], also plays a role in targeting LADs to the nuclear periphery [68]. 
A FISH-based screen of factors mediating (re)positioning of a set of loci towards the nuclear periphery [91] has identified chromatin modifiers, nuclear envelope proteins, and DNA replication and repair factors as candidates. However, there seems to be no universal factor targeting loci to the periphery: one factor may be implicated in targeting several loci, and one locus may be targeted by more than one factor [91]. Context dependency is probably a key variable, such as cell cycle stage, transcription status, or chromatin state. For example, peripheral targeting of loci has been shown to depend on H3K27me3 at LAD borders [68], G9a-mediated H3K9me2 of sequences flanking LADs or SUV39H-mediated H3K9me3 [92], and in Caenorhabditis elegans, step-wise H3K9 methylation [57]. Identification of locus-positioning factors is a critical task in light of pathologies manifested by chromatin reorganization at the nuclear periphery, such as in aging or certain cancers $[19,93,94]$.

\section{How do LADs identified in cell ensembles translate in single cells? LAD detection in single cells by DamID}

A major advancement in our understanding of LAD behavior is single-cell lamin DamID [15, 95]. A tour de force of nearly 400 single-cell DamID experiments reveals that LADs contacting the nuclear lamina with high frequency are extremely gene-poor, supporting a structural role of cLADs [95]. More variable LADs display less consistency between cells in a population and tend to be specific to a given cell type. Laminchromatin contacts may not occur as independent events, but appear to be coordinated intrachromosomally to form LADs in regions found to interact in $\mathrm{Hi}-\mathrm{C}$ data [95]. This is reminiscent of the formation of intrachromosomal repressive TAD cliques which acquire lamin association and localize at the nuclear periphery [8].

\section{Not all LADs localize at the nuclear periphery}

Imaging of LADs using FISH using probes, and 3D genome structure modeling data, concurs in that only $\sim 30 \%$ of LADs identified by sequencing map to the nuclear periphery $[14,15,95]$. This makes sense since there is arguably no space at periphery for all LADs found in ensemble methods, which represent up to $40 \%$ of the genome [18]. This illustrates the "ensemble versus single-cell" problem and heterogeneity of laminchromatin interactions between cells [96]. Cell-to-cell heterogeneity in chromatin conformation can be predicted from 3D genome models [14, 97-99] and shown by singlecell Hi-C [100] and by FISH $[8,14,101]$ (Fig. 3a, b).

\section{Single-cell analysis of LAD dynamics}

Examination of the 3D organization of LADs in entire chromosomes provides new insights on the role of chromatin-lamina associations in genome organization. FISHbased mapping of LADs and inter-LADs in single chromosomes reveals an arrangement of LADs in constrained domains at the nuclear lamina, which depends on underlying H3K9me2/3 and H3K27me3 and lamin A/C [69]. LADs are largely not stochastic between cells, supporting the structural role of these domains in nuclear architecture [69]. The imaging data also uncover small regions within LADs containing enhancers and TSSs, which escape the repressive environment of the nuclear periphery to interact with A compartment areas; these sites could correspond to escaper promoters [80]. 


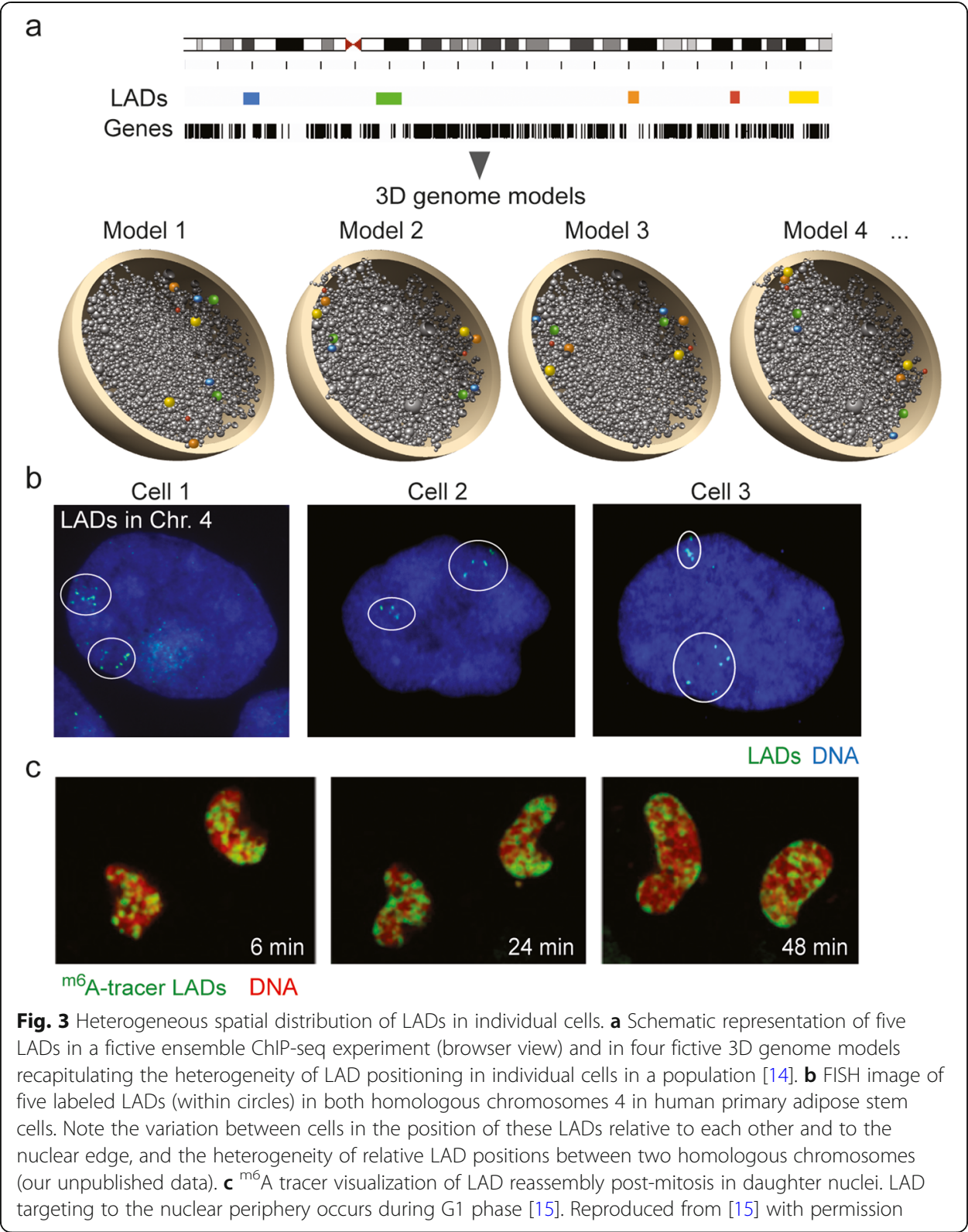

This altogether provides further evidence that LADs constitute discontinuous domains of lamina interaction.

Live-cell tracking of LADs using an ${ }^{\mathrm{m} 6} \mathrm{~A}$ tracer in single cells yields information on the dynamics of LADs during nuclear envelope reassembly after mitosis [15, 69] (Fig. 3c). B compartments are established before LAD formation [69]. LAD reformation after mitosis occurs as a step-wise process where LADs in the previous cell cycle display a stochastic distribution in anaphase and telophase [15] (Fig. 3c). During G1, however, LADs relocate to the nuclear periphery [15, 69] (Fig. 3c). The imaging data further suggest that peripheral LADs result from self-aggregation of several small domains in the nuclear interior preceding targeting to the nuclear envelope, with the lamina being resolved in late G1 [69]. This view concurs with the emergence of LADs from 
intrachromosomal interacting domains [95] in the nuclear interior after mitosis exit [15].

A pending issue in LAD characterization is that of allelic differences. Likely for practical reasons, this has been overlooked in most ensemble ChIP, DamID, or Hi-C analyses, but cannot be ignored in FISH [101] or ${ }^{\mathrm{m} 6} \mathrm{~A}$ tracer [15, 69] studies. Positioning of LADs relative to the nuclear periphery even reveals differences between homologous chromosomes [8] (Fig. 3b). Circumventing the issue of ploidy, the single-cell DamID mapping of LADs mentioned above was done in the quasi-haploid KBM7 cell line [95]. A recent allele-specific CRISPR live-cell DNA imaging method allows mapping individual alleles [102] and could be applied to characterize the radial dynamics of LADs.

\section{Euchromatic LADs}

\section{A-type lamins interact with euchromatin in the nucleoplasm}

Even though lamins are mainly found at the nuclear lamina, a pool of A-type lamins exists in the nuclear interior [103-107]. Given the role of A-type lamins in constraining chromatin mobility [33, 108], it is perhaps not surprising that nucleoplasmic A-type lamins interact with chromatin [30] and play a role in gene regulation [109]. What is the evidence?

A-type lamins associate with chromatin in the nucleoplasm in a manner dependent on the chromatin-bound LAP2 variant LAP2 $\alpha$, which directly binds lamin A exclusively in the nuclear interior [31]. There, lamin A interacts with euchromatic LADs overlapping with LAP2 $\alpha$ [32] (Fig. 4a). Depletion of LAP2 $\alpha$ eliminates the nucleoplasmic pool of lamin A and relocalizes it to the nuclear envelope where it binds heterochromatic domains consistent with typical LADs [32]. Association of lamin A with developmental promoters and enhancers (in the nuclear interior) coinciding with Polycomb repressor complex 2 (PRC2)- and H3K27me3-mediated gene repression has also been shown in pluripotent and multipotent cells [110-112] (Fig. 4a).

Evidence of euchromatic A-LADs also comes from methodological twists. (i) An antibody to lamin $\mathrm{A} / \mathrm{C}$ which preferentially recognizes its nucleoplasmic fraction immunoprecipitates mostly euchromatin, whereas an antibody preferentially detecting lamin A/ $\mathrm{C}$ at the nuclear lamina pulls down mostly heterochromatin [32]. (ii) Altering the chromatin sonication regime prior to ChIP can enrich "input" chromatin in euchromatic or heterochromatic regions [32]. This approach reveals a fraction of lamin A/C interacting with euchromatic LADs [32]. (iii) ChIP from chromatin fragmented with micrococcal nuclease also highlights associations of lamin A/C with LADs not typically heterochromatic and containing expressed genes [66]. The variability in chromatin composition and in gene expression patterns in lamin A/C-interacting domains suggests that lamin A/C-chromatin interactions may play different roles in genome organization and gene expression.

New in the neighborhood: phosphorylated lamin A binds active enhancers

Phosphorylation of A- and B-type lamins regulates their polymerization and nuclear envelope breakdown at mitosis [118]. Lamin A phosphorylation on serine S22 and S392 also occurs in the nucleoplasm in interphase [37], raising the possibility that phosphorylated lamin A could characterize the nucleoplasmic pool of A-type lamins [119]. 


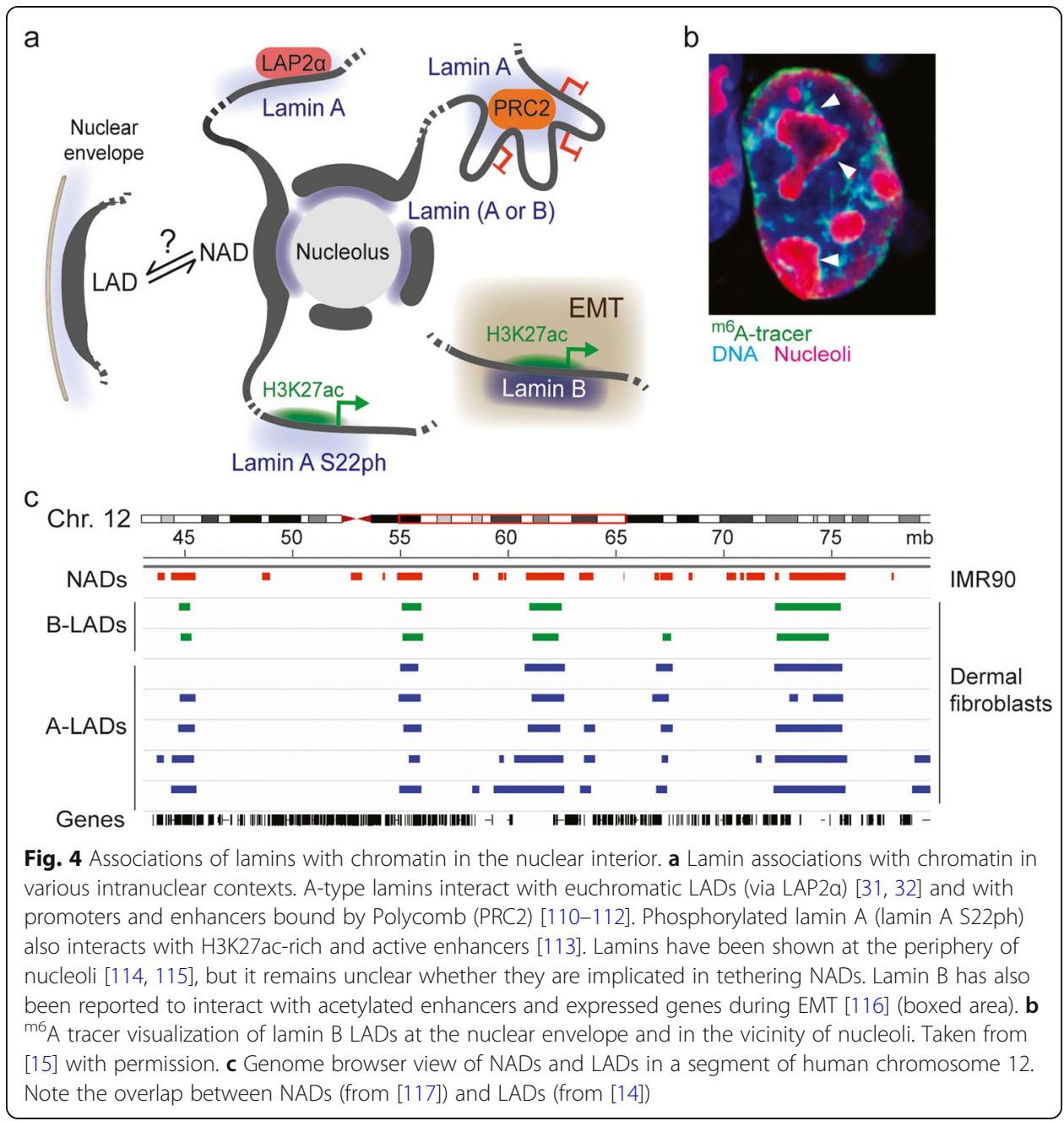

Lamin A phosphorylated on S22 (lamin A-S22ph) has been reported to bind active enhancers outside LADs [113] (Fig. 4a). In cells from patients with Hutchinson-Gilford Progeria Syndrome (HGPS), a premature aging syndrome caused by a mutation in lamin A [120], ectopic sites gaining lamin A-S22ph are relocalized in the nuclear interior and display increased H3K27ac [113]. These findings suggest new roles of A-type lamins in the regulation of enhancer activity. It will be important to determine whether other instances of association of these lamins with expressed genes [75] can also be explained by their phosphorylated state.

\section{Euchromatic LADs interacting with B-type lamins}

A fraction of B-type lamins has been found to interact with expressed genes, forming narrow euchromatic "e-LADs" during the epithelial-to-mesenchymal transition (EMT) [116] (Fig. 4a). How this might occur is intriguing. Permanent farnesylation of the Cterminus of B-type lamins a priori imposes a lipophilic environment for these lamins, which speculatively could be created by intranuclear lipid microdomains which have been suggested to act as transcription scaffolds [121] and regulators [122]. What lamin B does at active genes containing H3K27 acetylated enhancers [116], how it is targeted 
there, and whether it coincides with sites of phosphorylated lamin A [113] will be important to address.

\section{LADs and NADs-where should heterochromatin go?}

The nucleolus is the site of ribosome biogenesis where ribosomal DNA genes are grouped and transcribed in a manner dependent on cell growth, metabolism, and differentiation. Roles of the nucleolus also extend to chromatin organization. The nucleolus is a large membraneless organelle that clusters heterochromatin at its periphery in the form of nucleolus-associated domains (NADs) [9, 123] (Fig. 4a). So together with the nuclear lamina, the nucleolar periphery is a site of heterochromatin aggregation $[117,124]$ (Fig. 4b). NADs have been identified after biochemical isolation of nucleoli and sequencing of the associated DNA $[9,123]$ (Fig. 4c). NADs are B compartment regions of low gene density and low gene expression and strikingly overlap with LADs (Fig. 4c). NADs therefore display a striking resemblance to LADs, suggesting that the lamina and the nucleolus constitute interchangeable scaffolds for heterochromatin [15, 125] (Fig. 4a, b). NADs could also be LADs accumulating at the nucleolar periphery because lamins also seem to localize there in some cell types [114, 126] (Fig. 4a). What remains unknown is whether these represent distinct lamin fractions and how they might be targeted there, but intranuclear lipid aggregates [121, 122] could perhaps again be implicated.

\section{LADs and 3D genome topology}

\section{The INM and the nuclear lamina as a spatial nuclear organizer}

Association of the genome with INM proteins and the nuclear lamina provides a nuclear periphery perspective of spatial genome organization [11]. LBR plays a key role in tethering heterochromatin at the nuclear periphery in differentiating tissues, whereas this function is taken over by lamin $\mathrm{A} / \mathrm{C}$ in fully differentiated tissues [48]. However, while lamin $\mathrm{A} / \mathrm{C}$ or LBR are needed to stabilize peripheral heterochromatin, they are not drivers of heterochromatin assembly, which rather seems to result from a phase separation process involving CBX5 [127]. LBR peptides antagonize CBX5-mediated phase separation [128], in line with the idea that coalescence of heterochromatin can occur independently of nuclear envelope association. Assembly of heterochromatic TAD cliques without LADs [14] further precludes a role of the lamina in the assembly of large heterochromatin domains. This is also in line with the pre-formation of LADs as "lamin-free" intranuclear domains prior to nuclear envelope targeting [69]. However, interactions between heterochromatin and the lamina are necessary for peripheral tethering and to confer a "conventional" organization of chromatin [48, 129]. The importance of LADs in 3D genome topology is also evident from FISH observations that inactive parts of chromosomes interface the nuclear lamina while gene-rich and transcribed regions face the nucleoplasm $[69,130]$.

Loss of lamins in mouse ES cells causes detachment of peripheral chromatin from the lamina, hence LAD loss [71]. This is accompanied by a decondensation of cLADs, which $\mathrm{Hi}-\mathrm{C}$ data suggest is mediated by increased inter-TAD interactions and decreased chromosomal contacts within TADs, while TAD boundaries remain unaltered. Chromatin decondensation in cLADs does not reflect a chromosome-wide increase in 
volume, which contrasts with the impact of lamin B1 knockdown on chromosome decondensation in colon cancer cells [131]. So the impact of the lamina on chromatin organization seems to extend beyond LADs. Further supporting this view, knockdown of lamin $\mathrm{A} / \mathrm{C}$ increases the number of H3K4me3-marked promoters, yet without necessary changes in gene expression [75]. A lamin A network is also required for proper Polycomb targeting in the genome in myoblasts [110]. Moreover, chromatin compaction in LADs is accompanied by an increase in volume outside LADs in Drosophila cells, and depletion of the only Drosophila lamin type (Dm0) in these cells (Drosophila has two lamin genes, $\operatorname{LamC}$ and $\mathrm{DmO}$ ) causes chromatin expansion in LADs [132]. This argues for a role of lamins in shaping the 3D genome also in Drosophila.

\section{Relationship between TADs and LADs}

LADs and TADs together emerge as genome organizers in 3D structural models of the genome, at the whole-genome scale $[14,133]$ and in sub-chromosomal regions [134]. Whole-genome models take into account restraints imposed by TAD-TAD interactions (from Hi-C data) and TAD-lamina interactions (from lamin ChIP-seq data) [14, 133]. Introduction of a LAD constraint on TAD positioning in simulations ascribes TADs towards the nuclear periphery more frequently than if no such constraint is imposed. Similarly to FISH data [95], not all LADs are assigned to the periphery in all genome models [14] (Fig. 3a, b). Evidence for LADs and TADs acting in concert to organize genome topology is supported by $\mathrm{Hi}-\mathrm{C}$ showing assemblies of TAD cliques during differentiation, translocation of these cliques towards the nuclear periphery (inferred from 3D models), and stabilization at the nuclear lamina [8].

\section{LADs during embryogenesis: just the beginning}

When and how LADs form during development has long remained obscure. Recent DamID maps of chromatin interactions with the nuclear lamina in mouse embryos now shed light on this developmental event [135]. Embryonic nuclear organization is established de novo during the first cell cycles following fertilization. Allele-specific DNA FISH shows that the maternal and paternal genomes establish LADs with distinct features, with maternal LADs being more variable between cells and more euchromatic [135]. LAD formation seems to be independent of DNA replication and may on the paternal genome implicate H3K4 methylation [135]. Embryonic LAD formation seems to precede the detection of topological domains [135], revealing a step-wise assembly of embryonic genome topology.

\section{LADs as hotspots for de novo mutations}

LADs are preferred host domains for de novo DNA lesions, which are underrepresented in genes and regulatory regions $[136,137]$. LADs are also sensitive to reactive oxygen species and 8-oxoguanine [138]. This raises the question of whether peripheral heterochromatin, rich in repeats [139], would be more susceptible to DNA lesions than the rest of genome, acting as a "sink" for genetic alterations. A more plausible alternative is that DNA lesions are detected more frequently at the nuclear periphery than in the nuclear interior because the compact nature of heterochromatin restricts access to the DNA repair machinery [140,141]. 3D maps of mutations associated with 
melanomas also reveal a propensity of the most frequently occurring mutations to be enriched at the nuclear periphery, perhaps for the same reasons [137].

Interestingly, mechanical forces generated by transit of a cell through a micropore seem to preferentially disrupt spatial chromatin organization in B compartments, which contain LADs, over euchromatic A compartments [142]. This could be linked to the relative peripheral localization and rigidity [143] of heterochromatin which could lead to slow recovery from damage. The mechanical properties of heterochromatin could again protect active gene domains from disruption.

\section{Hand in hand: post-translational modifications of lamins and chromatin}

Nuclear lamins can be post-translationally modified by phosphorylation [37], $\beta-O-$ linked $\mathrm{N}$-acetylglucosamine (O-GlcNAc) modification [38], and acetylation [39]. Lamin A-O-GlcNAc [38] predominantly occurs at 11 sites in the C-terminal tail, between residues 385 and 646, which include the nucleosome-binding Ig fold [29]. This bulky nutrient-sensing modification of lamin A may affect nuclear lamina structure and hypothetically interactions of A-type lamins with chromatin. Integral proteins of the INM are also post-translationally modified [144], not only expanding the proteome of the nuclear envelope, but also plausibly modulating associations with the lamina and chromatin.

Lamin A acetylation is essential for maintenance of nuclear architecture and genome integrity [39]. Loss of acetylation results in enhanced lamin solubility, impaired phosphorylation, and mechanostability. It also results in nuclear blebs, a phenotype resulting from disease-causing lamin A mutations [20], and in chromatin anomalies manifested by enrichment in H3K27me3, reduction in H3K27ac and reduced chromatin accessibility [39]. Lamin acetylation could therefore potentially affect interactions with chromatin. Acetylation of lamin A at lysine K311 may be health-relevant: expression of the lamin A acetylation-deficient K311R mutant causing a muscle dystrophy [145] phenocopies chromatin modifications elicited by the loss of the lamin $\mathrm{A} / \mathrm{C}$ acetylase complex [39], implicating lamin A/C acetylation in laminopathies.

\section{Implications of LADs in disease}

LADs and cancer: links remain speculative

Cancer cells are characterized by changes in their epigenome akin to changes in gene expression [146]. Alterations in DNA content through genomic duplications and deletions, along with deformations of the nuclear envelope [21], suggest impairments also in associations of the nuclear lamina with chromatin. However, LADs have not systematically been examined to date, despite their mapping in several cancer cell lines [16, 77]. One limiting factor may be the probable variability in LADs between cells within a tumor which could exceed LAD variations between normal diploid cells [94]. So there is to date no evidence of systematic alterations in LADs during cellular transformation, or of any causal link between LADs and cancer [22, 94].

\section{Laminopathies and LADs}

A causal link between mutations in A-type lamins and Emery-Dreifuss muscular dystrophy has been established over two decades ago [147]. Since, $\sim 500$ mutations 
throughout the LMNA gene have been connected to $\sim 15$ diseases commonly called laminopathies. These diseases exhibit distinct or partly overlapping phenotypes and include muscle dystrophies, partial lipodystrophies, peripheral neuropathies, and HGPS [19]. Nuclei of cells from laminopathy patients typically show nuclear membrane deformations (Fig. 5a). Several lamin A mutations affect interactions with chromatin, epigenomes, and genome conformation. Expression of lamin A mutants linked to a progeroid syndrome (lamin A [L647R]) [148] or to a congenital lipodystrophy and muscle dystrophy (lamin A [R388P]) [149] results in LAD differences consistent with the peripheral (L647R) or nucleoplasmic (R388P) localization of these mutants [14]. Accordingly, 3D genome models incorporating $\mathrm{Hi}-\mathrm{C}$ data and LADs generated by expression of these mutants predict distinct LAD radial association densities [14].

More relevant in a laminopathy context is the mapping of LADs in fibroblasts from patients with the lamin A (R482W) mutation causing familial partial lipodystrophy of Dunnigan type (FPLD2). This mutation lies in the Ig-like fold of lamin A and perturbs DNA and nucleosome binding in vitro [29, 150]. Lamin A LADs in FPLD2 fibroblasts and 3D genome modeling reveal patient-specific LADs in the nuclear interior containing genes relevant for adipose tissue differentiation and function [14]. Alterations in chromatin conformation inferred from these findings are another manifestation of large-scale chromatin changes in HGPS, such as the loss of LADs and of heterochromatin at the nuclear periphery $[24,26]$.

However, whether LAD defects observed in overexpression systems and in cultured patient cells are the primary causes of cellular and organismal pathologies remains questioned because changes in LADs are usually minor [14, 151]. Recent data also indicate that $\mathrm{A} / \mathrm{B}$ re-compartmentalization elicited by a cardiomyopathy-causing lamin A truncation in an induced pluripotent stem cell model of the disease can hardly be

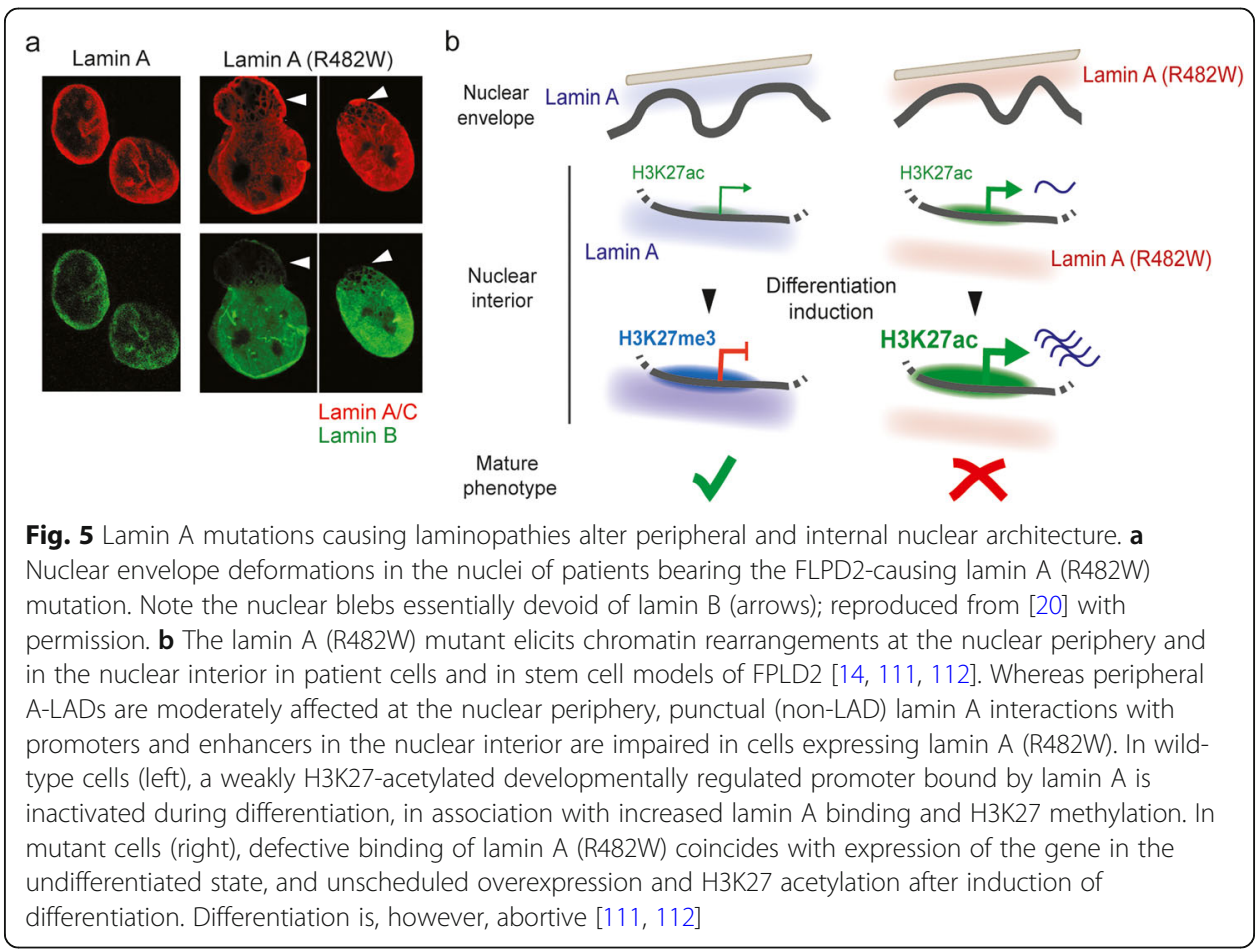


linked to the pathophysiology in this model [152]. Thus, LAD alterations associated with lamin A mutations do not necessarily support a hypothesis of chromatin defects being at the origin of laminopathies.

\section{Local impact of lamin mutations on promoters and enhancers}

On the other hand, during EMT, lamin B1 binds ectopically to the TSS of highly expressed genes [116], and in HGPS cells, lamin A-S22ph is found at enhancers showing elevated H3K27ac [113]. Accordingly, the FPLD2-causing lamin A (R482W) mutation is associated with local defects in chromatin organization (Fig. 5b). In an adipose stem cell model, expression of the mutation results in increased reduced H3K27me3, increased H3K27ac, and increased looping (suggested by FISH) of a distal enhancer onto the anti-adipogenic microRNA MIR335 gene, concordant with its overexpression and abortive adipogenesis [112]. Defective Polycomb-mediated repression similarly emerges from an induced pluripotent stem cell model of FPLD2 focusing on endothelial differentiation [111], and from ectopic H3K27me3 in myoblasts expressing a muscle dystrophy-causing lamin A mutation [110]. These studies suggest that defective lamin binding could underline pathology phenotypes.

Even though LADs, punctual inter-LAD lamin-chromatin interactions, and chromatin topologies may be altered in models of laminopathies, the chromatin defects reported above might nonetheless be secondary or parallel to structural tissue and cellular perturbations, inferring mechanotransduction perturbations to the nuclear lamina and the genome. Studies will need to disentangle direct gene regulatory effects from impacts of the mutations on the mechanotransduction apparatus.

\section{Perspectives}

Evidence for structural heterogeneity of the nuclear lamina and LADs prompts further investigations on mechanisms regulating local variations in lamin-chromatin interactions within LADs and variable punctual interactions in inter-LADs. The detection of LADs with preferences for A- or B-type lamins warrants investigations on whether these occur at the nuclear lamina and through what mechanism, and whether they are related to the formation of microdomains of lamins $A / C$ and $B$ in the lamina. These observations also raise the question of if and how stoichiometry of A- and B-type lamins, which varies with tissue stiffness [153], influences LADs and radial chromatin distribution. Similarly, to what extent lamina structure and the distribution of lamin A and lamin B LADs are affected by disease-causing lamin A mutations is unknown.

Phosphorylation of lamin A/C provides a hint on the importance of posttranslational lamin modifications on chromatin binding and enhancer activity [113] and gene regulation in a more global sense. The binding of lamin B1 on enhancers that are activated during EMT however remains intriguing [116]. Are these interactions regulatory or does lamin binding occur to "seal the deal," locking a chromatin conformation in place? The lamin A (K311R) prevents lamin A/C acetylation at this residue, which leads to nuclear envelope deformation, lower chromatin accessibility, and histone acetylation defects [39], indicating a direct involvement of A-type lamins in local chromatin composition and gene regulation. Similarly, how lamin A mutations affect lamin 
modifications, including the nutrient-sensing GlcNAcylation, remains unexplored territory.

Increasing awareness of not only between-cell variations, but also variations between homologous chromosomes in LADs and spatial chromatin arrangement [101], raises the issue of whether there are allele-specific LADs. Single-cell imaging approaches in polymorphic backgrounds should provide insights on chromosome-specific LADs and on whether regulation of imprinted gene expression might also involve lamin interactions.

More remains to be learned on the relationship between mechanical tension and stress, the nuclear lamina, LADs, and genome architecture. Nuclear volume differs between cells cultured in 2D or 3D. Increase of nuclear volume is accompanied by chromatin expansion, unfolding of the nuclear lamina, and increase in nucleolar volume [154]. As such, changes in nuclear size and shape during cell migration may impact gene expression by altering 3D chromatin architecture [142]. What are the consequences of unfolding the nuclear lamina on lamin-chromatin interactions, chromatin compaction in LADs, epigenetic marks, and gene expression in these regions? Are LADs at all maintained and if so, are they structurally altered? A 3D chemo-mechanical model to describe a 3-way feedback between cell adhesion, cytoskeleton, and the nucleus has been proposed [155]. The model argues that tensile stress regulates properties of the nucleus and chromatin, including lamin A/C levels, chromatin stiffness, and histone acetylation. The data lead to the view that the nuclear lamina is a mechanosensing mediator of tensile stress. Should these effects be mediated through LADs, impacts on chromatin architecture and gene expression may be anticipated [156].

Interactions of lamins with the genome turn out to be a lot more subtle and complex than originally described. Domain versus punctual interactions, nuclear periphery versus internal interactions, LAD heterogeneity and dynamics between cells, lamin modifications and disease-causing lamin mutations altering LADs, epigenomes and the 3D conformation of chromatin make the study of LADs as genomic organizers more exciting than ever.

\section{Supplementary information}

Supplementary information accompanies this paper at https://doi.org/10.1186/s13059-020-02003-5.

Additional file 1. Review history.

\section{Abbreviations}

3D: Three-dimensional; ChIP-seq: Chromatin immunoprecipitation sequencing; DamID: Dam identification; FISH: Fluorescence in situ hybridization; FPLD2: Familial Partial Lipodystrophy of Dunnigan Type; GFP: Green fluorescent protein; HGPS: Hutchinson-Gilford Progeria Syndrome; INM: Inner nuclear membrane; LAD: Laminaassociated domain; CLAD: Constitutive LAD; vLAD: Variable LAD; NAD: Nucleolus-associated domain; NPC: Nuclear pore complex; ONM: Outer nuclear membrane; TAD: Topologically associated domain

Review history

The review history is available as Additional file 1.

Peer review information

Anahita Bishop was the primary editor on this article and managed its editorial process and peer review in collaboration with the rest of the editorial team. 


\section{Funding}

The authors are supported by the Research Council of Norway, the Norwegian Cancer Society, and the Norwegian South-East Health Authorities.

\section{Competing interests}

The authors declare that they have no competing interests.

Published online: 02 April 2020

\section{References}

1. Rowley MJ, Corces VG. Organizational principles of 3D genome architecture. Nat Rev Genet. 2018;19:789-800.

2. Zheng $\mathrm{H}, \mathrm{Xie} \mathrm{W}$. The role of $3 \mathrm{D}$ genome organization in development and cell differentiation. Nat Rev Mol Cell Biol. 2019;20:535-50.

3. Lieberman-Aiden E, van Berkum NL, Williams L, Imakaev M, Ragoczy T, Telling A, Amit I, Lajoie BR, Sabo PJ, Dorschner $\mathrm{MO}$, et al. Comprehensive mapping of long-range interactions reveals folding principles of the human genome. Science. 2009;326:289-93.

4. Dekker J, Marti-Renom MA, Mirny LA. Exploring the three-dimensional organization of genomes: interpreting chromatin interaction data. Nat Rev Genet. 2013;14:390-403.

5. Rao SS, Huntley MH, Durand NC, Stamenova EK, Bochkov ID, Robinson JT, Sanborn AL, Machol I, Omer AD, Lander ES, Aiden EL. A 3D map of the human genome at kilobase resolution reveals principles of chromatin looping. Cell. 2014; 159:1665-80.

6. Quinodoz SA, Ollikainen N, Tabak B, Palla A, Schmidt JM, Detmar E, Lai MM, Shishkin AA, Bhat P, Takei Y, et al. Higherorder inter-chromosomal hubs shape 3D genome organization in the nucleus. Cell. 2018;174:744-57.

7. Szabo Q, Jost D, Chang JM, Cattoni DI, Papadopoulos GL, Bonev B, Sexton T, Gurgo J, Jacquier C, Nollmann M, et al. TADs are 3D structural units of higher-order chromosome organization in Drosophila. Sci Adv. 2018;4:eaar8082.

8. Paulsen J, Liyakat Ali TM, Nekrasov M, Delbarre E, Baudement MO, Kurscheid S, Tremethick D, Collas P. Long-range interactions between topologically associating domains shape the four-dimensional genome during differentiation. Nat Genet. 2019;51:835-43.

9. van Koningsbruggen S, Gierlinski M, Schofield P, Martin D, Barton GJ, Ariyurek Y, den Dunnen JT, Lamond Al. Highresolution whole-genome sequencing reveals that specific chromatin domains from most human chromosomes associate with nucleoli. Mol Biol Cell. 2010;21:3735-48.

10. Chen Y, Zhang Y, Wang Y, Zhang L, Brinkman EK, Adam SA, Goldman R, van Steensel B, Ma J, Belmont AS. Mapping 3D genome organization relative to nuclear compartments using TSA-Seq as a cytological ruler. J Cell Biol. 2018;217:402548.

11. Buchwalter A, Kaneshiro JM, Hetzer MW. Coaching from the sidelines: the nuclear periphery in genome regulation. Nat Rev Genet. 2019;20:39-50.

12. Burke B, Stewart CL. The nuclear lamins: flexibility in function. Nat Rev Mol Cell Biol. 2013;14:13-24.

13. Meuleman W, Peric-Hupkes D, Kind J, Beaudry JB, Pagie L, Kellis M, Reinders M, Wessels L, van Steensel B. Constitutive nuclear lamina-genome interactions are highly conserved and associated with A/T-rich sequence. Genome Res. 2013;23: 270-80.

14. Paulsen J, Sekelja M, Oldenburg AR, Barateau A, Briand N, Delbarre E, Shah A, Sørensen AL, Vigouroux C, Buendia B, Collas P. Chrom3D: three-dimensional genome modeling from Hi-C and lamin-genome contacts. Genome Biol. 2017;18: 21.

15. Kind J, Pagie L, Ortabozkoyun H, Boyle S, de Vries SS, Janssen H, Amendola M, Nolen LD, Bickmore WA, van Steensel B. Single-cell dynamics of genome-nuclear lamina interactions. Cell. 2013;153:178-92.

16. Lund EG, Oldenburg AR, Collas P. Enriched Domain Detector: a program for detection of wide genomic enrichment domains robust against local variations. Nucleic Acids Res. 2014;42:e92

17. Rønningen T, Shah A, Oldenburg AR, Vekterud K, Delbarre E, Moskaug JO, Collas P. Prepatterning of differentiationdriven nuclear lamin A/C-associated chromatin domains by GlcNAcylated histone H2B. Genome Res. 2015;25:1825-35.

18. Guelen L, Pagie L, Brasset E, Meuleman W, Faza MB, Talhout W, Eussen BH, de KA, Wessels L, de Laat W, van Steensel B. Domain organization of human chromosomes revealed by mapping of nuclear lamina interactions. Nature. 2008;453: 948-951.

19. Worman HJ. Nuclear lamins and laminopathies. J Pathol. 2012;226:316-25.

20. Vigouroux C, Auclair M, Dubosclard E, Pouchelet M, Capeau J, Courvalin JC, Buendia B. Nuclear envelope disorganization in fibroblasts from lipodystrophic patients with heterozygous R482Q/W mutations in the lamin A/C gene. J Cell Sci. 2001;114:4459-68.

21. Reddy KL, Feinberg AP. Higher order chromatin organization in cancer. Semin Cancer Biol. 2013;23:109-15.

22. Madakashira BP, Sadler KC. DNA methylation, nuclear organization, and cancer. Front Genet. 2017:8:76.

23. Scaffidi P, Misteli T. Reversal of the cellular phenotype in the premature aging disease Hutchinson-Gilford progeria syndrome. Nat Med. 2005;11:440-5.

24. Shumaker DK, Dechat T, Kohlmaier A, Adam SA, Bozovsky MR, Erdos MR, Eriksson M, Goldman AE, Khuon S, Collins FS, et al. Mutant nuclear lamin A leads to progressive alterations of epigenetic control in premature aging. Proc Natl Acad Sci U S A. 2006;103:8703-8.

25. Taimen P, Pfleghaar K, Shimi T, Moller D, Ben-Harush K, Erdos MR, Adam SA, Herrmann H, Medalia O, Collins FS, et al. A progeria mutation reveals functions for lamin A in nuclear assembly, architecture, and chromosome organization. Proc Natl Acad Sci U S A. 2009;106:20788-93.

26. McCord R, Nazario-Toole A, Zhang H, Chines P, Zhan Y, Erdos M, Collins F, Dekker J, Cao K. Correlated alterations in genome organization, histone methylation, and DNA-lamin A/C interactions in Hutchinson-Gilford progeria syndrome. Genome Res. 2013;23:260-9. 
27. Shah PP, Donahue G, Otte GL, Capell BC, Nelson DM, Cao K, Aggarwala V, Cruickshanks HA, Rai TS, McBryan T, et al. Lamin B1 depletion in senescent cells triggers large-scale changes in gene expression and the chromatin landscape. Genes Dev. 2013;27:1787-99.

28. Turgay Y, Eibauer M, Goldman AE, Shimi T, Khayat M, Ben-Harush K, Dubrovsky-Gaupp A, Sapra KT, Goldman RD, Medalia O. The molecular architecture of lamins in somatic cells. Nature. 2017;543:261-4.

29. Stierle V, Couprie J, Ostlund C, Krimm I, Zinn-Justin S, Hossenlopp P, Worman HJ, Courvalin JC, Duband-Goulet I. The carboxyl-terminal region common to lamins A and C contains a DNA binding domain. Biochemistry. 2003;42:4819-28.

30. Dechat T, Gesson K, Foisner R. Lamina-independent lamins in the nuclear interior serve important functions. Cold Spring Harb Symp Quant Biol. 2010;75:533-43.

31. Dechat T, Korbei B, Vaughan OA, VIcek S, Hutchison CJ, Foisner R. Lamina-associated polypeptide 2alpha binds intranuclear A-type lamins. J Cell Sci. 2000;113:3473-84.

32. Gesson K, Rescheneder P, Skoruppa MP, von HA, Dechat T, Foisner R. A-type lamins bind both hetero- and euchromatin, the latter being regulated by lamina-associated polypeptide 2 alpha. Genome Res 2016;26:462-473.

33. Bronshtein I, Kepten E, Kanter I, Berezin S, Lindner M, Redwood AB, Mai S, Gonzalo S, Foisner R, Shav-Tal Y, Garini Y. Loss of lamin A function increases chromatin dynamics in the nuclear interior. Nat Commun. 2015;6:8044.

34. Xie W, Chojnowski A, Boudier T, Lim JS, Ahmed S, Ser Z, Stewart C, Burke B. A-type Lamins form distinct filamentous networks with differential nuclear pore complex associations. Curr Biol. 2016;26:2651-8.

35. Shimi T, Pfleghaar K, Kojima S, Pack CG, Solovei I, Goldman AE, Adam SA, Shumaker DK, Kinjo M, Cremer T, Goldman RD. The A- and B-type nuclear lamin networks: microdomains involved in chromatin organization and transcription. Genes Dev. 2008;22:3409-21.

36. Shimi T, Kittisopikul M, Tran J, Goldman AE, Adam SA, Zheng Y, Jagaman K, Goldman RD. Structural organization of nuclear lamins A, C, B1, and B2 revealed by superresolution microscopy. Mol Biol Cell. 2015;26:4075-86.

37. Kochin V, Shimi T, Torvaldson E, Adam SA, Goldman A, Pack CG, Melo-Cardenas J, Imanishi SY, Goldman RD, Eriksson JE. Interphase phosphorylation of lamin A. J Cell Sci. 2014;127:2683-96.

38. Simon DN, Wriston A, Fan Q, Shabanowitz J, Florwick A, Dharmaraj T, Peterson SB, Gruenbaum Y, Carlson CR, GronningWang LM, et al. OGT (O-GlcNAc Transferase) selectively modifies multiple residues unique to lamin A. Cells. 2018;7:E44.

39. Karoutas A, Szymanski W, Rausch T, Guhathakurta S, Rog-Zielinska EA, Peyronnet R, Seyfferth J, Chen HR, de Leeuw R, Herquel B, et al. The NSL complex maintains nuclear architecture stability via lamin A/C acetylation. Nat Cell Biol. 2019; 21:1248-60.

40. Delbarre E, Tramier M, Coppey-Moisan M, Gaillard C, Courvalin JC, Buendia B. The truncated prelamin A in HutchinsonGilford progeria syndrome alters segregation of A-type and B-type lamin homopolymers. Hum Mol Genet. 2006;15: 1113-22.

41. Kittisopikul M, Virtanen L, Taimen P, Goldman RD. Quantitative analysis of nuclear lamins imaged by super-resolution light microscopy. Cells. 2019;8:E361.

42. Malik P, Korfali N, Srsen V, Lazou V, Batrakou DG, Zuleger N, Kavanagh DM, Wilkie GS, Goldberg MW, Schirmer EC. Cellspecific and lamin-dependent targeting of novel transmembrane proteins in the nuclear envelope. Cell Mol Life Sci. 2010;67:1353-69.

43. Zuleger N, Boyle S, Kelly DA, de Las Heras Jl, Lazou V, Korfali N, Batrakou DG, Randles KN, Morris GE, Harrison DJ, et al. Specific nuclear envelope transmembrane proteins can promote the location of chromosomes to and from the nuclear periphery. Genome Biol. 2013;14:R14.

44. Czapiewski R, Robson MI, Schirmer EC. Anchoring a leviathan: how the nuclear membrane tethers the genome. Front Genet. 2016;7:82.

45. Robson MI, de Las Heras Jl, Czapiewski R, Le Thanh P, Booth DG, Kelly DA, Webb S, Kerr ARW, Schirmer EC. Tissuespecific gene repositioning by muscle nuclear membrane proteins enhances repression of critical developmental genes during myogenesis. Mol Cell. 2016;62:834-47.

46. Harr JC, Gonzalez-Sandoval A, Gasser SM. Histones and histone modifications in perinuclear chromatin anchoring: from yeast to man. EMBO Rep. 2016;17:139-55.

47. Ye $\mathrm{Q}$, Worman $\mathrm{HJ}$. Interaction between and integral protein of the nuclear envelope inner membrane and human chromodomain proteins homologous to Drosophila HP1. J Biol Chem. 1996;271:14653-6.

48. Solovei I, Wang AS, Thanisch K, Schmidt CS, Krebs S, Zwerger M, Cohen TV, Devys D, Foisner R, Peichl L, et al. LBR and lamin A/C sequentially tether peripheral heterochromatin and inversely regulate differentiation. Cell. 2013;152:584-98.

49. Foisner $R$, Gerace $L$. Integral membrane proteins of the nuclear envelope interact with lamins and chromosomes, and binding is modulated by mitotic phosphorylation. Cell. 1993;73:1267-79.

50. Furukawa K. LAP2 binding protein 1 (L2BP1/BAF) is a candidate mediator of LAP2-chromatin interaction. J Cell Sci. 1999; 112:2485-92

51. Dechat T, Vlcek S, Foisner R. Review: lamina-associated polypeptide 2 isoforms and related proteins in cell cycledependent nuclear structure dynamics. J Struct Biol. 2000;129:335-45.

52. Barton LJ, Soshnev AA, Geyer PK. Networking in the nucleus: a spotlight on LEM-domain proteins. Curr Opin Cell Biol. 2015;34:1-8.

53. Demmerle J, Koch AJ, Holaska JM. The nuclear envelope protein emerin binds directly to histone deacetylase 3 (HDAC3) and activates HDAC3 activity. J Biol Chem. 2012;287:22080-8.

54. Somech R, Shaklai S, Geller O, Amariglio N, Simon AJ, Rechavi G, Gal-Yam EN. The nuclear-envelope protein and transcriptional repressor LAP2beta interacts with $\mathrm{HDAC} 3$ at the nuclear periphery, and induces histone $\mathrm{H} 4$ deacetylation. J Cell Sci. 2005;118:4017-25.

55. Zullo JM, Demarco IA, Pique-Regi R, Gaffney DJ, Epstein CB, Spooner CJ, Luperchio TR, Bernstein BE, Pritchard JK, Reddy $\mathrm{KL}$, Singh $\mathrm{H}$. DNA sequence-dependent compartmentalization and silencing of chromatin at the nuclear lamina. Cell. 2012;149:1474-87.

56. Demmerle J, Koch AJ, Holaska JM. Emerin and histone deacetylase 3 (HDAC3) cooperatively regulate expression and nuclear positions of MyoD, Myf5, and Pax7 genes during myogenesis. Chromosom Res. 2013;21:765-79.

57. Towbin BD, Gonzalez-Aguilera C, Sack R, Gaidatzis D, Kalck V, Meister P, Askjaer P, Gasser SM. Step-wise methylation of histone H3K9 positions heterochromatin at the nuclear periphery. Cell. 2012;150:934-47. 
58. Gonzalez-Sandoval A, Towbin BD, Kalck V, Cabianca DS, Gaidatzis D, Hauer MH, Geng L, Wang L, Yang T, Wang X, et al. Perinuclear anchoring of H3K9-methylated chromatin stabilizes induced cell fate in C. elegans embryos. Cell. 2015;163: $1333-47$.

59. Mattout A, Cabianca DS, Gasser SM. Chromatin states and nuclear organization in development--a view from the nuclear lamina. Genome Biol. 2015;16:174.

60. Cabianca DS, Munoz-Jimenez C, Kalck V, Gaidatzis D, Padeken J, Seeber A, Askjaer P, Gasser SM. Active chromatin marks drive spatial sequestration of heterochromatin in C. elegans nuclei. Nature. 2019;569:734-9.

61. Yao J, Fetter RD, Hu P, Betzig E, Tjian R. Subnuclear segregation of genes and core promoter factors in myogenesis. Genes Dev. 2011;25:569-80.

62. Luperchio TR, Wong X, Reddy KL. Genome regulation at the peripheral zone: lamina associated domains in development and disease. Curr Opin Genet Dev. 2014;25:50-61.

63. Marchal C, Sima J, Gilbert DM. Control of DNA replication timing in the 3D genome. Nat Rev Mol Cell Biol. 2019;20:72137.

64. Peric-Hupkes D, Meuleman W, Pagie L, Bruggeman SW, Solovei I, Brugman W, Graf S, Flicek P, Kerkhoven RM, van Lohuizen $\mathrm{M}$, et al. Molecular maps of the reorganization of genome-nuclear lamina interactions during differentiation. Mol Cell. 2010;38:603-13.

65. Sadaie M, Salama R, Carroll T, Tomimatsu K, Chandra T, Young AR, Narita M, Perez-Mancera PA, Bennett DC, Chong H, et al. Redistribution of the Lamin B1 genomic binding profile affects rearrangement of heterochromatic domains and SAHF formation during senescence. Genes Dev. 2013;27:1800-8.

66. Lund EG, Duband-Goulet I, Oldenburg A, Buendia B, Collas P. Distinct features of lamin A-interacting chromatin domains mapped by ChIP-sequencing from sonicated or micrococcal nuclease-digested chromatin. Nucleus. 2015;6:30-8

67. Aughey GN, Cheetham SW, Southall TD. DamID as a versatile tool for understanding gene regulation. Development 2019;146. https://doi.org/10.1242/dev.173666.

68. Harr JC, Luperchio TR, Wong X, Cohen E, Wheelan SJ, Reddy KL. Directed targeting of chromatin to the nuclear lamina is mediated by chromatin state and A-type lamins. J Cell Biol. 2015;208:33-52.

69. Luperchio TR, Sauria MEG, Hoskins VE, Wong X, DeBoy E, Gaillard M-C, Tsang P, Pekrun K, Ach RA, Yamada NA, et al. The repressive genome compartment is established early in the cell cycle before forming the lamina associated domains. bioRxiv. 2018. https://doi.org/10.1101/481598.

70. Chen S, Luperchio TR, Wong X, Doan EB, Byrd AT, Roy Choudhury K, Reddy KL, Krangel MS. A lamina-associated domain border governs nuclear lamina interactions, transcription, and recombination of the Tcrb locus. Cell Rep. 2018;25:172940 e6.

71. Zheng X, Hu J, Yue S, Kristiani L, Kim M, Sauria M, Taylor J, Kim Y, Zheng Y. Lamins organize the global threedimensional genome from the nuclear periphery. Mol Cell. 2018:71:802-15.

72. Ghosh S, Liu B, Wang Y, Hao Q, Zhou Z. Lamin A is an endogenous SIRT6 activator and promotes SIRT6-mediated DNA repair. Cell Rep. 2015;13:1396-406.

73. Akhtar W, de Jong J, Pindyurin AV, Pagie L, Meuleman W, de Ridder J, Berns A, Wessels LF, van Lohuizen M, van Steensel B. Chromatin position effects assayed by thousands of reporters integrated in parallel. Cell. 2013;154:914-27.

74. Finlan LE, Sproul D, Thomson I, Boyle S, Kerr E, Perry P, Ylstra B, Chubb JR, Bickmore WA. Recruitment to the nuclear periphery can alter expression of genes in human cells. PLoS Genet. 2008:4:e1000039.

75. Lund E, Oldenburg A, Delbarre E, Freberg C, Duband-Goulet I, Eskeland R, Buendia B, Collas P. Lamin A/C-promoter interactions specify chromatin state-dependent transcription outcomes. Genome Res. 2013;23:1580-9.

76. Robson MI, de Las Heras Jl, Czapiewski R, Sivakumar A, Kerr ARW, Schirmer EC. Constrained release of lamina-associated enhancers and genes from the nuclear envelope during T-cell activation facilitates their association in chromosome compartments. Genome Res. 2017;27:1126-38.

77. Forsberg F, Brunet A, Ali TML, Collas P. Interplay of lamin A and lamin B LADs on the radial positioning of chromatin. Nucleus. 2019;10:7-20.

78. Brunet A, Forsberg F, Fan Q, Sæther T, Collas P. Nuclear lamin B1 interactions with chromatin during the circadian cycle are uncoupled from periodic gene expression. Front Genet. 2019;10:917.

79. Wu F, Yao J. Identifying novel transcriptional and epigenetic features of nuclear lamina-associated genes. Sci Rep. 2017; 7:100

80. Leemans C, van der Zwalm MCH, Brueckner L, Comoglio F, van Schaik T, Pagie L, van Arensbergen J, van Steensel B. Promoter-intrinsic and local chromatin features determine gene repression in LADs. Cell. 2019;177:852-64 e14.

81. Ikegami K, Egelhofer TA, Strome S, Lieb JD. Caenorhabditis elegans chromosome arms are anchored to the nuclear membrane via discontinuous association with LEM-2. Genome Biol. 2010;11:R120.

82. Poleshko A, Shah PP, Gupta M, Babu A, Morley MP, Manderfield LJ, Ifkovits JL, Calderon D, Aghajanian H, Sierra-Pagan JE, et al. Genome-nuclear lamina interactions regulate cardiac stem cell lineage restriction. Cell. 2017;171:573-87.

83. Reddy KL, Zullo JM, Bertolino E, Singh H. Transcriptional repression mediated by repositioning of genes to the nuclear lamina. Nature. 2008;452:243-7.

84. Vivante A, Brozgol E, Bronshtein I, Levi V, Garini Y. Chromatin dynamics governed by a set of nuclear structural proteins. Genes Chrom Cancer. 2018. https://doi.org/10.1002/gcc.22719.

85. Reinke H, Asher G. Crosstalk between metabolism and circadian clocks. Nat Rev Mol Cell Biol. 2019;20:227-41.

86. Takahashi JS. Transcriptional architecture of the mammalian circadian clock. Nat Rev Genet. 2017:18:164-79.

87. Kim YH, Marhon SA, Zhang Y, Steger DJ, Won KJ, Lazar MA. Rev-erbalpha dynamically modulates chromatin looping to control circadian gene transcription. Science. 2018;359:1274-7.

88. Pacheco-Bernal I, Becerril-Perez F, Aguilar-Arnal L. Circadian rhythms in the three-dimensional genome: implications of chromatin interactions for cyclic transcription. Clin Epigenetics. 2019;11:79.

89. Zhao H, Sifakis EG, Sumida N, Millan-Arino L, Scholz BA, Svensson JP, Chen X, Ronnegren AL, Mallet de Lima CD, Varnoosfaderani FS, et al. PARP1- and CTCF-mediated interactions between active and repressed chromatin at the lamina promote oscillating transcription. Mol Cell. 2015;59:984-97.

90. Atchison L, Ghias A, Wilkinson F, Bonini N, Atchison ML. Transcription factor YY1 functions as a PcG protein in vivo. EMBO J. 2003;22:1347-58. 
91. Shachar S, Voss TC, Pegoraro G, Sciascia N, Misteli T. Identification of gene positioning factors using high-throughput imaging mapping. Cell. 2015;162:911-23.

92. Bian Q, Khanna N, Alvikas J, Belmont AS. beta-Globin cis-elements determine differential nuclear targeting through epigenetic modifications. J Cell Biol. 2013;203:767-83.

93. Lenain C, de Graaf CA, Pagie L, Visser NL, de Haas M, de Vries SS, Peric-Hupkes D, van Steensel B, Peeper DS. Massive reshaping of genome-nuclear lamina interactions during oncogene-induced senescence. Genome Res. 2017;27:1634-44.

94. Lochs SJA, Kefalopoulou S, Kind J. Lamina associated domains and gene regulation in development and cancer. Cells. 2019;8:271.

95. Kind J, Pagie L, de Vries SS, Nahidiazar L, Dey SS, Bienko M, Zhan Y, Lajoie B, de Graaf CA, Amendola M, et al. Genomewide maps of nuclear lamina interactions in single human cells. Cell. 2015;163:134-47.

96. Yanez-Cuna JO, van Steensel B. Genome-nuclear lamina interactions: from cell populations to single cells. Curr Opin Genet Dev. 2017;43:67-72.

97. Dai C, Li W, Tjong H, Hao S, Zhou Y, Li Q, Chen L, Zhu B, Alber F, Jasmine ZX. Mining 3D genome structure populations identifies major factors governing the stability of regulatory communities. Nat Commun. 2016;7:11549.

98. Kalhor R, Tjong H, Jayathilaka N, Alber F, Chen L. Genome architectures revealed by tethered chromosome conformation capture and population-based modeling. Nat Biotechnol. 2012;30:90-8.

99. Tjong H, Li W, Kalhor R, Dai C, Hao S, Gong K, Zhou Y, Li H, Zhou XJ, Le Gros MA, et al. Population-based 3D genome structure analysis reveals driving forces in spatial genome organization. Proc Natl Acad Sci U S A. 2016;113:E1663-E72.

100. Nagano T, Lubling Y, Stevens TJ, Schoenfelder S, Yaffe E, Dean W, Laue ED, Tanay A, Fraser P. Single-cell Hi-C reveals cell-to-cell variability in chromosome structure. Nature. 2013;502:59-64.

101. Finn EH, Pegoraro G, Brandao HB, Valton AL, Oomen ME, Dekker J, Mirny L, Misteli T. Extensive heterogeneity and intrinsic variation in spatial genome organization. Cell. 2019;176:1502-15 e10.

102. Maass PG, Barutcu AR, Shechner DM, Weiner CL, Mele M, Rinn JL. Spatiotemporal allele organization by allele-specific CRISPR live-cell imaging (SNP-CLING). Nat Struct Mol Biol. 2018;25:176-84.

103. Barboro P, D'Arrigo C, Diaspro A, Mormino M, Alberti I, Parodi S, Patrone E, Balbi C. Unraveling the organization of the internal nuclear matrix: RNA-dependent anchoring of NuMA to a lamin scaffold. Exp Cell Res. 2002;279:202-18

104. Bridger JM, Kill IR, O'Farrell M, Hutchison CJ. Internal lamin structures within G1 nuclei of human dermal fibroblasts. J Cell Sci. 1993;104:297-306.

105. Goldman AE, Moir RD, Montag-Lowy M, Stewart M, Goldman RD. Pathway of incorporation of microinjected lamin A into the nuclear envelope. J Cell Biol. 1992;119:725-35.

106. Naetar N, Korbei B, Kozlov S, Kerenyi MA, Dorner D, Kral R, Gotic I, Fuchs P, Cohen TV, Bittner R, et al. Loss of nucleoplasmic LAP2alpha-lamin A complexes causes erythroid and epidermal progenitor hyperproliferation. Nat Cell Biol. 2008;10:1341-8.

107. Kolb T, Maass K, Hergt M, Aebi U, Herrmann H. Lamin A and lamin C form homodimers and coexist in higher complex forms both in the nucleoplasmic fraction and in the lamina of cultured human cells. Nucleus. 2011;2:425-33.

108. Melcer S, Hezroni H, Rand E, Nissim-Rafinia M, Skoultchi A, Stewart CL, Bustin M, Meshorer E. Histone modifications and lamin A regulate chromatin protein dynamics in early embryonic stem cell differentiation. Nat Commun. 2012;3:910-1.

109. Naetar N, Ferraioli S, Foisner R. Lamins in the nuclear interior - life outside the lamina. J Cell Sci. 2017;130:2087-96.

110. Cesarini E, Mozzetta C, Marullo F, Gregoretti F, Gargiulo A, Columbaro M, Cortesi A, Antonelli L, Di Pelino S, Squarzoni S, et al. Lamin A/C sustains PcG protein architecture, maintaining transcriptional repression at target genes. J Cell Biol. 2015;211:533-51.

111. Briand N, Guenantin AC, Jeziorowska D, Shah A, Mantecon M, Capel E, Garcia M, Oldenburg A, Paulsen J, Hulot JS, et al. The lipodystrophic hotspot lamin A p.R482W mutation deregulates the mesodermal inducer T/Brachyury and early vascular differentiation gene networks. Hum Mol Genet. 2018;27:1447-59.

112. Oldenburg A, Briand N, Sorensen AL, Cahyani I, Shah A, Moskaug JO, Collas P. A lipodystrophy-causing lamin A mutant alters conformation and epigenetic regulation of the anti-adipogenic MIR335 locus. J Cell Biol. 2017;216:2731-43.

113. Ikegami K, Secchia S, Lleb JD, Moskoswitz IP. Phosphorylated Lamin A targets active enhancers and is associated with abnormal transcriptional activation in progeria. bioRxiv. 2019. https://doi.org/10.1101/682260

114. Sen Gupta A, Sengupta K. Lamin B2 modulates nucleolar morphology, dynamics, and function. Mol Cell Biol. 2017;37: e00274-17.

115. Buchwalter A, Hetzer MW. Nucleolar expansion and elevated protein translation in premature aging. Nat Commun. 2017:8:328.

116. Pascual-Reguant L, Blanco E, Galan S, Le Dily F, Cuartero Y, Serra-Bardenys G, Di Carlo V, Iturbide A, Cebria-Costa JP, Nonell $L$, et al. Lamin B1 mapping reveals the existence of dynamic and functional euchromatin lamin B1 domains. Nat Commun. 2018;9:3420.

117. Dillinger S, Straub T, Nemeth A. Nucleolus association of chromosomal domains is largely maintained in cellular senescence despite massive nuclear reorganisation. PLoS One. 2017;12:e0178821.

118. Heald R, McKeon F. Mutations of phosphorylation sites in lamin A that prevent nuclear lamina disasembly in mitosis. Cell. 1990;61:579-89.

119. Torvaldson E, Kochin V, Eriksson JE. Phosphorylation of lamins determine their structural properties and signaling functions. Nucleus. 2015;6:166-71.

120. Worman HJ, Courvalin JC. Nuclear envelope, nuclear lamina, and inherited disease. Int Rev Cytol. 2005;246:231-79.

121. Cascianelli G, Villani M, Tosti M, Marini F, Bartoccini E, Magni MV, Albi E. Lipid microdomains in cell nucleus. Mol Biol Cell. 2008;19:5289-95.

122. Fernandes V, Teles K, Ribeiro C, Treptow W, Santos G. Fat nucleosome: role of lipids on chromatin. Prog Lipid Res. 2018; 70:29-34.

123. Nemeth A, Conesa A, Santoyo-Lopez J, Medina I, Montaner D, Peterfia B, Solovei I, Cremer T, Dopazo J, Langst G. Initial genomics of the human nucleolus. PLoS Genet. 2010;6:e1000889.

124. Vertii A, Ou J, Yu J, Yan A, Pages H, Liu H, Zhu LJ, Kaufman PD. Two contrasting classes of nucleolus-associated domains in mouse fibroblast heterochromatin. Genome Res. 2019;29:1235-49.

125. Bersaglieri C, Santoro R. Genome organization in and around the nucleolus. Cells. 2019;8:E579. 
126. Martin C, Chen S, Maya-Mendoza A, Lovric J, Sims PF, Jackson DA. Lamin B1 maintains the functional plasticity of nucleoli. J Cell Sci. 2009;122:1551-62.

127. Strom AR, Emelyanov AV, Mir M, Fyodorov DV, Darzacq X, Karpen GH. Phase separation drives heterochromatin domain formation. Nature. 2017;547:241-5.

128. Larson AG, Elnatan D, Keenen MM, Trnka MJ, Johnston JB, Burlingame AL, Agard DA, Redding S, Narlikar GJ. Liquid droplet formation by HP1alpha suggests a role for phase separation in heterochromatin. Nature. 2017;547:236-40.

129. Falk M, Feodorova Y, Naumova N, Imakaev M, Lajoie BR, Leonhardt H, Joffe B, Dekker J, Fudenberg G, Solovei I, Mirny LA. Heterochromatin drives compartmentalization of inverted and conventional nuclei. Nature. 2019:570:395-9.

130. Bickmore WA, van Steensel B. Genome architecture: domain organization of interphase chromosomes. Cell. 2013;152: 1270-84.

131. Camps J, Wangsa D, Falke M, Brown M, Case CM, Erdos MR, Ried T. Loss of lamin B1 results in prolongation of S phase and decondensation of chromosome territories. FASEB J. 2014;28:3423-34.

132. Ulianov SV, Doronin SA, Khrameeva EE, Kos PI, Luzhin AV, Starikov SS, Galitsyna AA, Nenasheva W, Ilyin AA, Flyamer IM, et al. Nuclear lamina integrity is required for proper spatial organization of chromatin in Drosophila. Nat Commun. 2019; 10:1176.

133. Li Q, Tjong H, Li X, Gong K, Zhou XJ, Chiolo I, Alber F. The three-dimensional genome organization of Drosophila melanogaster through data integration. Genome Biol. 2017;18:145.

134. Chiang M, Michieletto D, Brackley CA, Rattanavirotkul N, Mohammed H, Marenduzzo D, Chandra T. Polymer modeling predicts chromosome reorganization in senescence. Cell Rep. 2019;28:3212-23 e6.

135. Borsos M, Perricone SM, Schauer T, Pontabry J, de Luca KL, de Vries SS, Ruiz-Morales ER, Torres-Padilla ME, Kind J. Genome-lamina interactions are established de novo in the early mouse embryo. Nature. 2019;569: 729-33.

136. Yoshihara M, Araki R, Kasama Y, Sunayama M, Abe M, Nishida K, Kawaji H, Hayashizaki Y, Murakawa Y. Hotspots of de novo point mutations in induced pluripotent stem cells. Cell Rep. 2017;21:308-15.

137. Garcia-Nieto PE, Schwartz EK, King DA, Paulsen J, Collas P, Herrera RE, Morrison AJ. Carcinogen susceptibility is regulated by genome architecture and predicts cancer mutagenesis. EMBO J. 2017:36:2829-43.

138. Yoshihara M, Jiang L, Akatsuka S, Suyama M, Toyokuni S. Genome-wide profiling of 8-oxoguanine reveals its association with spatial positioning in nucleus. DNA Res. 2014;21:603-12.

139. Vazquez BN, Thackray JK, Simonet NG, Chahar S, Kane-Goldsmith N, Newkirk SJ, Lee S, Xing J, Verzi MP, An W, et al. SIRT7 mediates L1 elements transcriptional repression and their association with the nuclear lamina. Nucleic Acids Res. 2019;47:7870-85

140. Amouroux R, Campalans A, Epe B, Radicella JP. Oxidative stress triggers the preferential assembly of base excision repair complexes on open chromatin regions. Nucleic Acids Res. 2010;38:2878-90.

141. Zheng CL, Wang NJ, Chung J, Moslehi H, Sanborn JZ, Hur JS, Collisson EA, Vemula SS, Naujokas A, Chiotti KE, et al. Transcription restores DNA repair to heterochromatin, determining regional mutation rates in cancer genomes. Cell Rep. 2014;9:1228-34.

142. Jacobson EC, Perry JK, Long DS, Olins AL, Olins DE, Wright BE, Vickers MH, O'Sullivan JM. Migration through a small pore disrupts inactive chromatin organization in neutrophil-like cells. BMC Biol. 2018;16:142.

143. Stephens AD, Liu PZ, Banigan EJ, Almassalha LM, Backman V, Adam SA, Goldman RD, Marko JF. Chromatin histone modifications and rigidity affect nuclear morphology independent of lamins. Mol Biol Cell. 2018;29:220-33.

144. Ryan CM, Souda P, Bassilian S, Ujwal R, Zhang J, Abramson J, Ping P, Durazo A, Bowie JU, Hasan SS, et al. Post-translational modifications of integral membrane proteins resolved by top-down Fourier transform mass spectrometry with collisionally activated dissociation. Mol Cell Proteomics. 2010;9:791-803.

145. Astejada MN, Goto K, Nagano A, Ura S, Noguchi S, Nonaka I, Nishino I, Hayashi YK. Emerinopathy and laminopathy clinical, pathological and molecular features of muscular dystrophy with nuclear envelopathy in Japan. Acta Myol. 2007; 26:159-64.

146. Timp W, Feinberg AP. Cancer as a dysregulated epigenome allowing cellular growth advantage at the expense of the host. Nat Rev Cancer. 2013:13:497-510.

147. Bonne G, di Barletta MR, Varnous S, Becane HM, Hammouda EH, Merlini L, Muntoni F, Greenberg CR, Gary F, Urtizberea $\mathrm{JA}$, et al. Mutations in the gene encoding lamin A/C cause autosomal dominant Emery-Dreifuss muscular dystrophy. Nat Genet. 1999;21:285-8.

148. Wang Y, Lichter-Konecki U, Anyane-Yeboa K, Shaw JE, Lu JT, Ostlund C, Shin JY, Clark LN, Gundersen GG, Nagy PL, Worman HJ. A mutation abolishing the ZMPSTE24 cleavage site in prelamin A causes a progeroid disorder. J Cell Sci. 2016;129:1975-80.

149. Barateau A, Vadrot N, Vicart P, Ferreiro A, Mayer M, Heron D, Vigouroux C, Buendia B. A novel lamin A mutant responsible for congenital muscular dystrophy causes distinct abnormalities of the cell nucleus. PLoS One. 2017;12: e0169189.

150. Duband-Goulet I, Woerner S, Gasparini S, Attanda W, Konde E, Tellier-Lebegue C, Craescu CT, Gombault A, Roussel P, Vadrot N, et al. Subcellular localization of SREBP1 depends on its interaction with the C-terminal region of wild-type and disease related A-type lamins. Exp Cell Res. 2011;317:2800-13.

151. Perovanovic J, Dell'Orso S, Gnochi VF, Jaiswal JK, Sartorelli V, Vigouroux C, Mamchaoui K, Mouly V, Bonne G, Hoffman EP. Laminopathies disrupt epigenomic developmental programs and cell fate. Sci Transl Med. 2016;8:335ra58.

152. Bertero A, Fields PA, Smith AST, Leonard A, Beussman K, Sniadecki NJ, Kim DH, Tse HF, Pabon L, Shendure J, et al. Chromatin compartment dynamics in a haploinsufficient model of cardiac laminopathy. J Cell Biol. 2019;218:2919-44.

153. Swift J, Ivanovska IL, Buxboim A, Harada T, Dingal PC, Pinter J, Pajerowski JD, Spinler KR, Shin JW, Tewari M, et al. Nuclear lamin-A scales with tissue stiffness and enhances matrix-directed differentiation. Science. 2013;341:1240104.

154. Katiyar A, Tocco VJ, Li Y, Aggarwal V, Tamashunas AC, Dickinson RB, Lele TP. Nuclear size changes caused by local motion of cell boundaries unfold the nuclear lamina and dilate chromatin and intranuclear bodies. Soft Matter. 2019;15: 9310-7. 
155. Alisafaei F, Jokhun DS, Shivashankar GV, Shenoy VB. Regulation of nuclear architecture, mechanics, and nucleocytoplasmic shuttling of epigenetic factors by cell geometric constraints. Proc Natl Acad Sci U S A. 2019;116: 13200-9.

156. Osmanagic-Myers S, Foisner R. The structural and gene expression hypotheses in laminopathic diseases-not so different after all. Mol Biol Cell. 2019;30:1786-90.

\section{Publisher's Note}

Springer Nature remains neutral with regard to jurisdictional claims in published maps and institutional affiliations.

Ready to submit your research? Choose BMC and benefit from:

- fast, convenient online submission

- thorough peer review by experienced researchers in your field

- rapid publication on acceptance

- support for research data, including large and complex data types

- gold Open Access which fosters wider collaboration and increased citations

- maximum visibility for your research: over $100 \mathrm{M}$ website views per year

At $\mathrm{BMC}$, research is always in progress.

Learn more biomedcentral.com/submissions 